From The University of Texas Health Science Center at San Antonio and Institute for Drug Development, Cancer Therapy and Research Center, San Antonio, TX

Submitted July 30, 2004; accepted July 14, 2005.

The authors have participated as investigators in several clinical studies of sorafenib funded by Bayer Corporation Pharmaceutical Division, New Haven, CT.

Authors' disclosures of potential conflicts of interest are found at the end of this article.

Address reprint requests to Eric $K$. Rowinsky, MD, 11710 Spotted Eagle, San Antonio, TX, 78248; e-mail: erowinsk@oncodrugs.com.

(C) 2005 by American Society of Clinical Oncology

0732-183X/05/2327-6771/\$20.00

DOI: $10.1200 / J C O .2005 .08 .036$

\title{
Raf: A Strategic Target for Therapeutic Development Against Cancer
}

\author{
Muralidhar Beeram, Amita Patnaik, and Eric K. Rowinsky
}

\section{$\begin{array}{lllllllll}\text { A } & \mathbf{B} & \mathbf{S} & \mathbf{T} & \mathbf{R} & \mathbf{A} & \mathbf{C} & \mathbf{T}\end{array}$}

The mitogen-activated protein kinase (MAPK) signaling pathway plays a critical role in transmitting proliferative signals generated by cell surface receptors and cytoplasmic signaling elements to the nucleus. Several important signaling elements of the MAPK pathway, particularly Ras and Raf, are encoded by oncogenes, and as such, their structures and functions can be modified, rendering them constitutively active. Because the MAPK pathway is dysregulated in a notable proportion of human malignancies, many of its aberrant and critical components represent strategic targets for therapeutic development against cancer. Raf, which is an essential serine/threonine kinase constituent of the MAPK pathway and a downstream effector of the central signal transduction mediator Ras, is activated in a wide range of human malignancies by aberrant signaling upstream of the protein (eg, growth factor receptors and mutant Ras) and activating mutations of the protein itself, both of which confer a proliferative advantage. Three isoforms of Raf have been identified, and therapeutics targeting Raf, including small-molecule inhibitors and antisense oligodeoxyribonucleotides (ASON), are undergoing clinical evaluation. The outcomes of these investigations may have far-reaching implications in the management of many types of human cancer. This review outlines the structure and diverse functions of Raf, the rationale for targeting Raf as a therapeutic strategy against cancer, and the present status of various therapeutic approaches including ASONs and small molecules, particularly sorafenib (BAY 43-9006).

J Clin Oncol 23:6771-6790. (C) 2005 by American Society of Clinical Oncology

\section{INTRODUCTION}

The ras family of oncogenes and encoded proteins has been evaluated as a putative target for anticancer therapeutic development. These efforts have resulted in new insights into Rasmediated cell signaling as it relates to human cancer. Ras plays a central role in an intricate array of signal transduction pathways, characterized by cross talk, feedback loops, and multicomponent signaling complexes. ${ }^{1-3}$ One strategy to overcome the challenges inherent in developing therapeutics against signaling elements situated in redundant pathways is to target elements downstream of convergence points of critical signaling modules. This reasoning has led, in part, to interest in Raf kinase, which is one of several downstream effectors of Ras, as a target for therapeutic development against cancer.

The Raf serine/threonine kinases are the principal effectors of Ras in the mitogen- activated protein kinase (MAPK) pathway (Fig 1). Raf activation occurs immediately downstream of membrane and cytoplasmic receptors that relay mitogenic signals. ${ }^{4} \mathrm{Al}$ though principally activated by Ras, Raf may also be activated by Ras-independent elements and, in turn, propagates signals through diverse effectors that mediate proliferation, angiogenesis, metastases, and survival. ${ }^{5}$ Raf may be activated by signaling upstream or constitutively. Constitutive activation of Raf and Ras are indistinguishable in their potential to induce malignant transformation. ${ }^{6-8}$ Activating raf mutations have been identified in melanoma, thyroid, colon, and other cancers ( $\mathrm{Ta}$ ble 1). ${ }^{9-43}$ Furthermore, the disappointing clinical results of farnesyltransferase (FTase) inhibitors (FTIs) that were developed based on a flawed premise that they would effectively target malignancies with a high incidence of Ras mutation has led to scrutiny of signaling elements downstream of Ras, such 


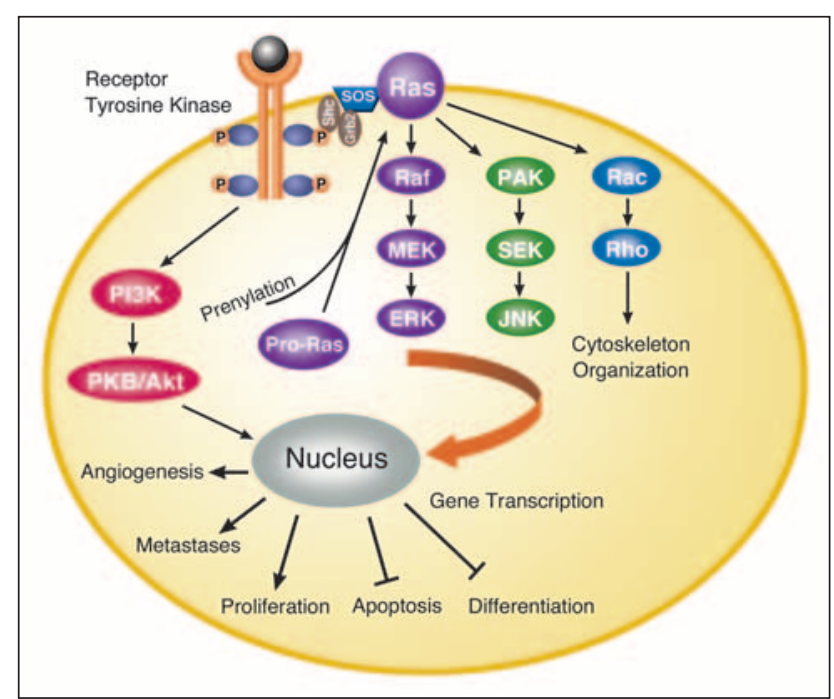

Fig 1. Ras-mediated signal transduction pathways. Abbreviations: PKB/Akt, protein kinase B; ERK, extracellular signal-regulated kinase; Grb2, growth factor receptor binding protein; JNK, c-JUN amino-terminal kinase; MEK, mitogen-activated protein kinase kinase; $\mathrm{P}$, phosphate; PAK, p21-activated kinase kinase or JNK kinase; PI3K, phosphatidylinositol 3-kinase; Shc, Sro homology domain-cytosol; SEK, stress-activated protein kinase; and SOS, son-of-sevenless exchange factor.

as Raf, as therapeutic targets. ${ }^{44}$ This review highlights relevant information about the biology of Raf and novel strategies directed at exploiting this knowledge to more effectively treat malignant diseases.

\section{SIGNALING THROUGH THE MAPK PATHWAY}

The molecular mechanisms and signaling pathways that regulate cell proliferation and survival are receiving considerable attention as potential targets for anticancer strategies. ${ }^{45,46}$ Recently, there has been a notable increase in efforts directed at targeting the MAPK pathway, which integrates a wide array of proliferative signals initiated by receptor tyrosine kinases (RTKs) and G protein-coupled receptors. ${ }^{47,48}$ The network of signals emanating from the MAPK pathway are transmitted by proteins that serve as chemical switches, cycling between phosphorylated (activated) and dephosphorylated (inactivated) states. ${ }^{49}$ These on and off switches are regulated by kinases and phosphatases, respectively. Activated signaling elements, in turn, phosphorylate amino acid residues on downstream signaling proteins in a cascade-like and expansive manner. ${ }^{50}$ Not only does the centrality of the MAPK pathway render its components important targets for therapeutic development, but many genes that encode for its critical signaling elements undergo mutations, constitutively activating downstream signaling elements and conferring the potential for transformation and autonomous growth. ${ }^{50-52}$ In addition to efforts directed at Ras, therapeutic strategies directed at the MAPK pathway are targeting the cascade of downstream effector proteins including Raf, MAPK kinase (MAPKK; also called MEK or extracellular signal-regulated kinase [ERK] kinase), and ERK. The Raf/MEK/ERK module (Fig 1) of the MAPK pathway, which is immediately downstream of Ras, may be less redundant and innately resistant to therapeutic manipulations compared with Ras (as discussed in the next section).

\section{The Unfilled Promise of Targeting Ras}

The Raf/MEK/ERK module of the MAPK pathway has been the focus of considerable attention because therapeutic efforts directed at Ras, which is situated at the apex of the MAPK pathway, have been disappointing. ${ }^{44}$ Ras belongs to a superfamily of guanine nucleotide triphosphatases (GTPases) that transmit proliferative and survival signals to the MAPK, phosphatidylinositol 3-kinase (PI3K), and other pathways (Figs 1 and 2). Three ras proto-oncogenes encode four $21-\mathrm{kd}$ proteins, called $\mathrm{p} 21^{\text {ras }}$ or Ras (H-Ras, $\mathrm{N}$-Ras, K-Ras4A, and K-Ras4B, resulting from two alternatively spliced $K$-Ras gene products), that are localized to the inner surface of the cell membrane. ${ }^{44}$ Of the three ras genes, $K$-ras mutations are most commonly found in solid malignancies, whereas $N$-ras mutations are encountered less often, and $H$-ras mutations are rarely encountered. ${ }^{53,54}$ Ras isoforms impart distinct biologic effects as a result of the potential of these proteins to differentially activitate critical effectors. ${ }^{55}$

After synthesis as inactive cytosolic propeptides, Ras undergoes a series of post-translational modifications at its carboxyl terminus that increase its hydrophobicity. ${ }^{56,57}$ These modifications render Ras functional and capable of localizing to the lipid-rich inner surface of the cell membrane. The first and most critical modification, farnesylation, which is principally catalyzed by protein FTase, adds a 15-carbon hydrobobic farnesyl isoprenyl tail to the carboxyl terminus of Ras. It is in the cell membrane where Ras cycles between inactive guanosine diphosphate-bound and active guanosine triphosphate (GTP) - bound states, thereby activating a series of effector kinases that phosphorylate a cascade of signaling proteins. ${ }^{58}$ Ras mutants exhibit slightly less intrinsic GTPase activity than wild-type Ras; however, the principal consequence of the mutated proteins is a marked decrease in interactions between Ras and its GTPase activator protein. ${ }^{59}$ Instead of reverting to its inactive guanosine diphosphate-bound state, the modified conformation of mutant Ras favors its active GTP-bound state, which has a higher propensity to activate downstream effectors even in the absence of growth factor stimulation, conferring a proliferative advantage to tumors.

The considerable attention paid to targeting Ras as a therapeutic strategy is based on the high incidence of activating ras mutations in human malignancies, including 


\begin{tabular}{|c|c|c|c|c|c|}
\hline $\begin{array}{l}\text { Raf } \\
\text { Isoform }\end{array}$ & $\begin{array}{l}\text { Predominant Genetic } \\
\text { Alterations }\end{array}$ & Type of Malignancy & Reference & $\begin{array}{l}\text { Frequency of Raf } \\
\text { Mutation }(\%)^{*}\end{array}$ & $\begin{array}{l}\text { Frequency of Ras } \\
\text { Mutation (\%) }\end{array}$ \\
\hline \multirow[t]{13}{*}{ B-Raf } & \multirow[t]{13}{*}{$\begin{array}{l}\text { Point (missense) } \\
\text { mutations }\end{array}$} & Malignant melanoma & $\begin{array}{l}\text { Davies et } \mathrm{al}^{9} \text { and Pollock and } \\
\text { Meltzer }\end{array}$ & $55-68$ & 16 \\
\hline & & Anaplastic thyroid carcinoma & Nikiforova et al ${ }^{15}$ & 83 & $-\dagger$ \\
\hline & & Papillary thyroid carcinoma & Kimura et $\mathrm{al}^{16}$ and Cohen et $\mathrm{al}^{18}$ & $35.8-69$ & 25 \\
\hline & & Cholangiocarcinoma & Tannapfel et al ${ }^{21}$ & $0-21$ & 56 \\
\hline & & Colorectal carcinoma & Rajagopalan et al ${ }^{14}$ & $4-16$ & 36 \\
\hline & & Esophageal carcinoma, Barrett's & Sommerer et $\mathrm{al}^{12}$ & 15 & $-\dagger$ \\
\hline & & Acute myeloid leukemia & Lee et $\mathrm{al}^{22}$ & 4 & 23 \\
\hline & & $\begin{array}{l}\text { Head and neck carcinoma, } \\
\text { squamous }\end{array}$ & Cohen et $\mathrm{al}^{19}$ and Weber et $\mathrm{al}^{23}$ & $3-4.8$ & 23 \\
\hline & & Lung carcinoma, non-small-cell & Brose et $\mathrm{al}^{24}$ & $2-3$ & 22 \\
\hline & & Gastric carcinoma & Lee et $\mathrm{al}^{25}$ & 2 & $-\dagger$ \\
\hline & & $\begin{array}{l}\text { Ovarian carcinoma, low-grade/ } \\
\text { high-grade }\end{array}$ & Singer et $\mathrm{al}^{20}$ & $63 / 0$ & 23 \\
\hline & & Mucinous ovarian carcinoma & Gemignani et $\mathrm{al}^{26}$ & 0 & 50 \\
\hline & & Non-Hodgkins lymphoma & Lee et $\mathrm{al}^{27}$ & 2 & $-\dagger$ \\
\hline \multirow[t]{11}{*}{ C-Raf } & \multirow[t]{11}{*}{$\begin{array}{l}\text { Gene rearrangements; } \\
\text { point mutations; } \\
\text { truncated amino- } \\
\text { terminal regulatory } \\
\text { domain }\end{array}$} & Renal cell carcinoma & Oka et $a^{28}$ & 55 & 10 \\
\hline & & Medullary thyroid carcinoma & Carson et $\mathrm{al}^{29}$ & $-\dagger$ & $-\dagger$ \\
\hline & & Breast carcinoma & $\begin{array}{l}\text { Callans et } \text { al }^{13} \text { and McFarlin and } \\
\text { Gould }\end{array}$ & $-\dagger$ & 2 \\
\hline & & Lung carcinoma, non-small-cell & Kerkhoff et $\mathrm{al}^{31}$ & $-\dagger$ & 22 \\
\hline & & Lung carcinoma, small-cell & Graziano et $\mathrm{al}^{32}$ & $>90$ & $<2$ \\
\hline & & $\begin{array}{l}\text { Head and neck carcinoma, } \\
\text { squamous }\end{array}$ & Patel et $\mathrm{al}^{33}$ and Riva et $\mathrm{al}^{34}$ & $-\dagger$ & 23 \\
\hline & & Soft tissue and bone sarcomas & Ikeda et $\mathrm{al}^{35}$ and Mitsunobu et al ${ }^{36}$ & $-\dagger$ & $-\dagger$ \\
\hline & & $\begin{array}{l}\text { CNS: glioma, glioblastoma, } \\
\text { ependymoma }\end{array}$ & $\begin{array}{l}\text { LaRocca et al, }{ }^{37} \text { Fukui et al, } \\
\quad \text { and Korshunov et } \mathrm{al}^{39}\end{array}$ & $-\dagger$ & $-\dagger$ \\
\hline & & Hepatocellular carcinoma & $\begin{array}{l}\text { Ting et al, }{ }^{40} \text { Jenke et } \mathrm{al}^{, 41} \text { and } \\
\text { Beer et } \mathrm{al}^{42}\end{array}$ & $-\dagger$ & 31 \\
\hline & & Pancreatic carcinoma & Berger et $\mathrm{al}^{43}$ & $-\dagger$ & 78 \\
\hline & & Non-Hodgkins lymphomas, T-cell & Storm and Rapp ${ }^{10}$ & $-\dagger$ & $-\dagger$ \\
\hline
\end{tabular}

approximately $22 \%$ of non-small-cell lung, $50 \%$ of colorectal, and $90 \%$ of pancreatic cancers. ${ }^{53,60,61}$ Of the strategies directed at Ras, targeting FTase has received the most attention, but the FTIs are not Ras specific, and a bonafide Ras-specific therapeutic agent has not yet been evaluated in clinical trials. ${ }^{62,63}$ Fortunately, because $K$-ras mutations constitute most ras mutations in the aforementioned malignancies, in which the therapeutic expectations of FTIs were among the highest, the failure of this strategy should not be surprising because geranylgeranyl transferase I can alternatively prenylate $K$-ras, rendering it functional even when FTase is completely inhibited. ${ }^{64,65}$ Although the FTIs have shown notable antitumor activity in patients with advanced breast cancer and some hematologic malignancies, the low ras mutation rates in these cancers suggest that farnesylation of other critical proteins is being inhibited. ${ }^{66}$

\section{DOWNSTREAM OF RAS: RAF AND OTHER RAS EFFECTORS}

Localization of GTP-bound Ras to the inner surface of the cell membrane activates several downstream effectors, most notably the serine/threonine kinase Raf, which is the first signaling element in the MAPK pathway. ${ }^{2,67,68}$ As shown in Figure 1, other downstream effectors of Ras include the PI3K cell survival pathway, the small GTP-binding proteins Rac and Rho, and the stress-activated protein kinase pathway (also referred to as the c-jun N-terminal kinase [JNK] pathway). ${ }^{69-71}$ In addition, in response to cellular stress and cytokine stimulation mediated through Ras, the dual-specificity $\mathrm{p} 38^{M A P K}$ kinases (MKK3 and MKK6) and the JNK kinases (MKK4 and MKK7) phosphorylate $\mathrm{p} 38^{\text {MAPK }}$ and JNK, respectively. ${ }^{72-76}$

GTP-bound Ras interacts directly with Raf and mobilizes the inactive protein from the cytoplasm (Figs 1 and 2). 


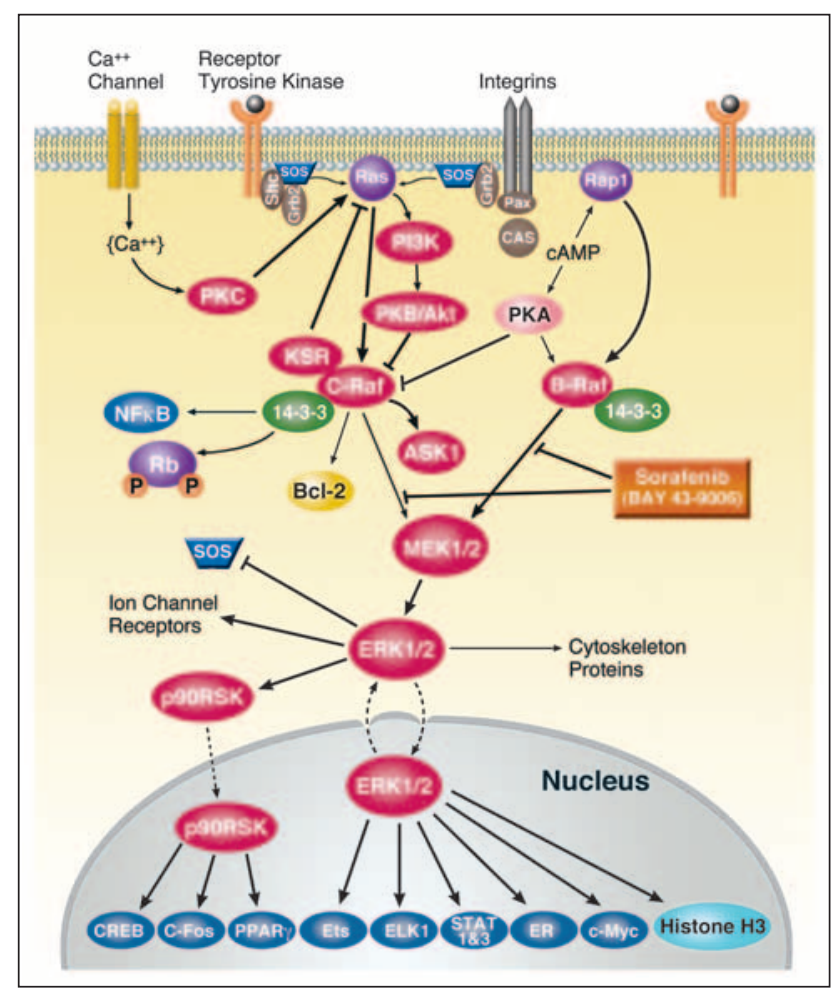

Fig 2. Raf is stimulated by diverse mitogenic stimuli and, in turn, activates multiple effectors. Abbreviations: ASK1, apoptosis signal-regulated kinase; CREB, cyclic adenosine monophosphate response element B; c-Fos, c-Myc, Ets, and ELK1, transcription factors; NF- $\kappa$ B, nuclear factor-kappa B; p90RSK, 90-kd ribosomal S6 kinase; PPAR $\gamma$, peroxisome proliferator activated receptor gamma; Rb, retinoblastoma protein; Shc, Src homology domain-cytosol; STAT, signal transducer and activator of transcription.

Once the Ras-Raf complex is translocated to the cell membrane, Ras activates the serine/threonine kinase function of Raf through an association between its Ras-binding domain (RBD) in the amino-terminal regulatory region and Ras-GTP. This is followed by a series of Ras-dependent phosphorylation events and conformational changes, which will be described later in this review. ${ }^{77-84}$ The regulatory mechanisms of various Raf isoforms differ in that A-Raf and C-Raf require additional phosphorylation reactions for activity, whereas B-Raf has a much higher level of basal kinase activity. ${ }^{85}$

Raf is also activated by Ras-independent activators, including the soluble non-RTK Src and Janus kinase 1, which are involved in cytokine signaling. ${ }^{86}$ Other Rasindependent activators of Raf include interferon beta, protein kinase C (PKC) alpha, antiapoptotic proteins (eg, Bcl-2), scaffolding proteins (eg, ceramide-activated protein kinase), ultraviolet light, ionizing radiation, retinoids, erythropoietin, and dimerization between Raf isoforms ${ }^{86-94}$ (Fig 3). In addition, several Raf mutations confer constitutive activity to Raf irrespective of signaling activity upstream. ${ }^{9,11,12}$ The multifactoral mechanisms of Raf activation imply that therapeutic strategies that depend on the abrogation of any single element of these pathways may not result in sufficiently robust tumor

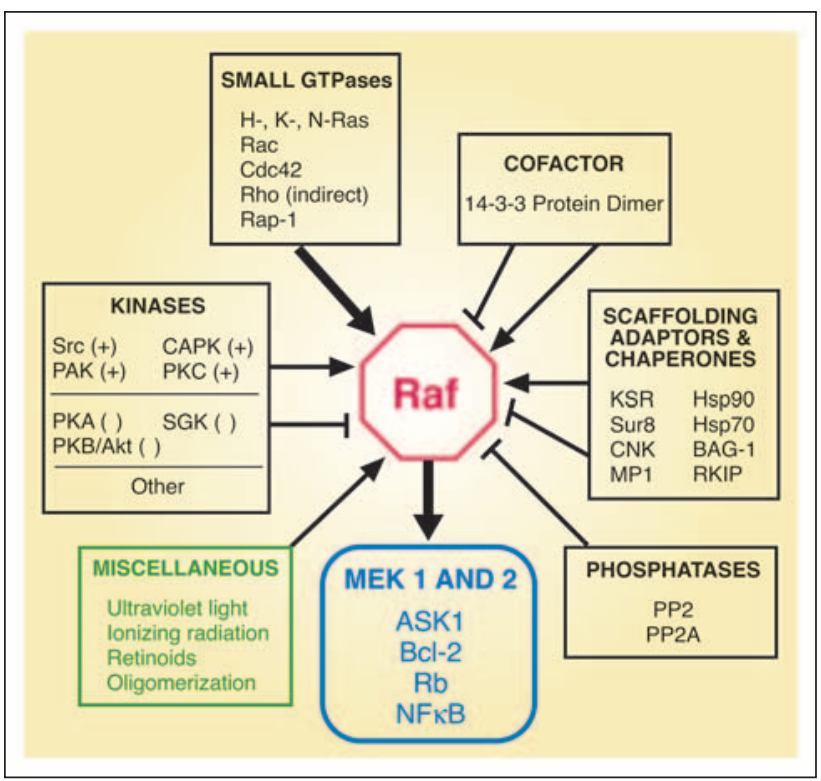

Fig 3. The activating and inhibitory stimuli converging on Raf and its principal downstream effectors. Abbreviations: ASK1, apoptosis signalregulated kinase; BAG1, Bcl2- associated athanogene; CAPK, ceramideactivated protein kinase; cdc42, cyclin-dependent kinase; Hsp, heat shock proteins; KSR, kinase suppressor of Ras; MP1, MEK partner-1; NF- $\kappa$ B nuclear factor-kappa B; PAK, p21-activated kinase; PKC, protein kinase C; PKB/Akt, protein kinase $\mathrm{B}$; PP1 and PP2A, protein phosphatases; Rap1, repressor activator protein $1 ; \mathrm{Rb}$, retinoblastoma protein; RKIP, Raf kinaseinhibitor protein; SGK, steroid glucocorticoid kinase; Src, soluble nonreceptor tyrosine kinase; (+), activator; $(-)$, inhibitor.

growth-inhibitory activity. Furthermore, the kinase activity of Raf is inhibited by its interactions with cholesterol-rich lipid rafts in the cell membrane and phosphorylation by protein kinases A (PKA) and B (PKB/Akt), as shown in Figure 2. ${ }^{95-98}$ In essence, the activation status of Raf depends on the integration of both activating and inhibitory stimuli, the net result of which determines the downstream messages.

\section{THE RAF FAMILY OF GENES AND PROTEINS}

The raf family of genes was first identified as oncogenes in retroviruses that are the causative vectors of tumors in mice and chicken. ${ }^{99,100}$ The first raf gene to be identified, $v$-raf, the transforming gene of the mouse sarcoma virus 3611, induces fibrosarcomas and erythroleukemia in newborn mice, and C-raf (also called raf-1) is its proto-oncogene homolog. ${ }^{101,102} A$-raf was found next by screening a mouse spleen cDNA library at low stringency with a $v$-raf probe. Next, $v$-Rmil was identified as the transforming gene in the avian retrovirus Mill Hill No. 2 ( $\mathrm{MH} 2$ ) from a spontaneous ovarian tumor and found to be homologous to $v$-raf. ${ }^{99}$ $C$-Rmil corresponded to a third mammalian raf gene, $B$-raf, which was also shown to be an oncogene. ${ }^{103,104}$ However, initial attempts to identify activated versions of raf in human cancers failed to demonstrate unique DNA rearrangements in 
any specific tumor type, which, in retrospect, can be attributed to the lack of requisite sensitivity of early assays to detect single point mutations. Furthermore, most early efforts were directed at $C$-raf, rather than at the more oncogenic $B$-raf.

The mammalian raf family consists of the following three genes: A-raf, B-raf, and C-raf, which are located on chromosomes Xp11, 7q32, and 3p25, respectively. The raf proto-oncogenes encode three 68- to 74-kd cytosolic proteins, termed A-Raf, B-Raf, and C-Raf (Raf-1), which share highly conserved amino-terminal regulatory regions and catalytic domains at the carboxyl terminus (Fig 4). ${ }^{10}$ As serine/threonine kinases, Raf proteins phosphorylate serine and threonine residues on essential modulatory proteins downstream of Ras. Each Raf species has a distinct expression profile in tissues, which suggests that individual Raf isoforms perform clearly defined functions. ${ }^{4} \mathrm{C}$-Raf is ubiq-

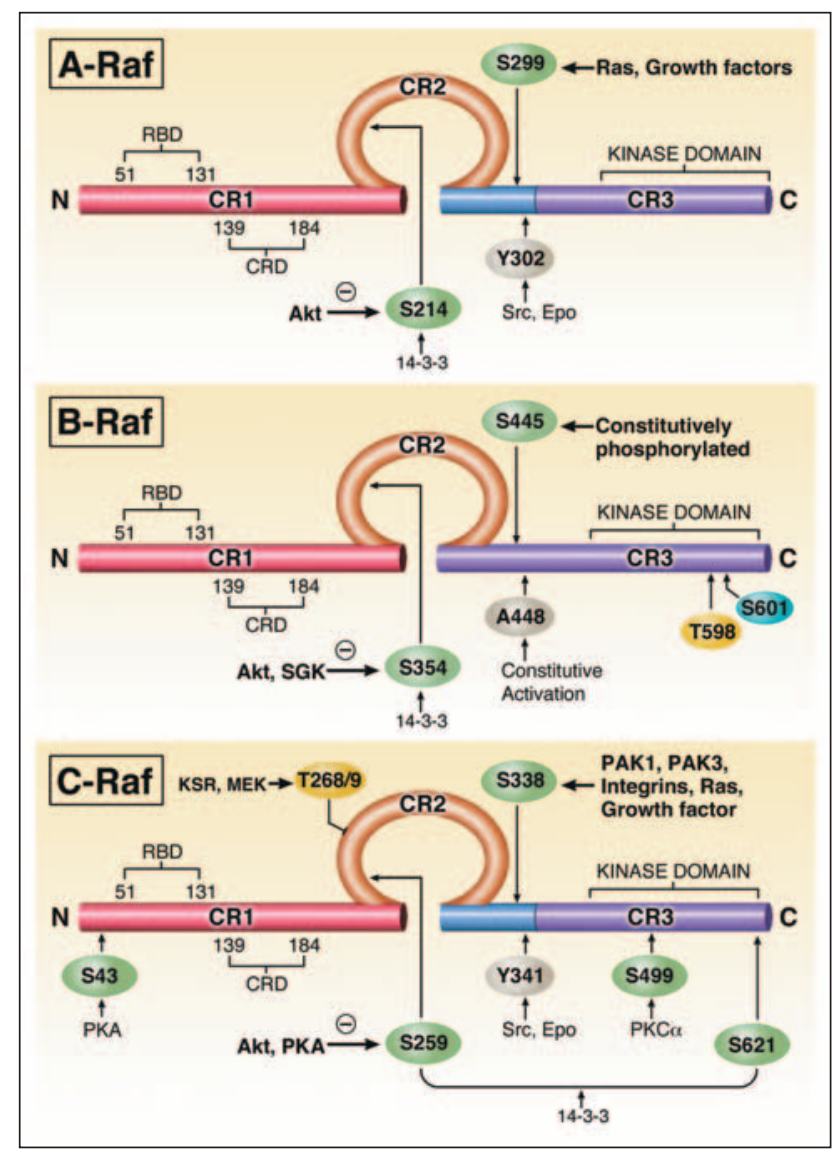

Fig 4. Schema of the domain structure of A-Raf, B-Raf, and C-Raf. The amino acid phosphorylation sites ( $\mathrm{S}$, serine; $\mathrm{T}$, threonine; $\mathrm{Y}$, tyrosine) and phosphorylating stimuli regulating the Raf kinases are shown. Abbreviations: C, N, carboxyl and amino terminus; RBD, Ras-binding domain; CRD, cysteine-rich domain; Epo, erythropoietin; KSR, kinase suppressor of Ras; MEK, mitogen-activated protein kinase kinase; PAK, p21-activated kinase; PKA, protein kinase $\mathrm{A}$; $\mathrm{PKC} \alpha$, protein kinase $\mathrm{C}$ alpha; SGK, steroid glucocorticoid kinase; Src, soluble nonreceptor tyrosine kinase. (Reproduced from Dowsett et al: Short-term changes in Ki-67 during neoadjuvant treatment of primary breast cancer with anastrozole or tamoxifen alone or combined correlate with recurrence-free survival. Clin Cancer Res 11:951S-958S, 2005) uitously expressed in most tissues. Both A- and B-Raf have more restricted expression profiles than C-Raf, with A-Raf overexpressed in urogenital tissues (eg, kidney, ovary, prostate, and epididymis) and B-Raf overexpressed in neural, testicular, splenic, and hematopoietic tissues. ${ }^{105}$ Unlike A-raf and C-raf, B-raf undergoes differential splicing in exons $8 \mathrm{~b}$ and $10 \mathrm{a}$, and its spliced variants are translated into 10 B-Raf isoforms. ${ }^{106,107}$ Both A-Raf and C-Raf undergo localization to the mitochondria, which supports the notion that Raf regulates apoptosis, but the specific proportions of Raf isoforms that are localized to the mitochondria are not known. ${ }^{108-112}$ This localization may be a result of isoform-specific lipid- or protein-binding partners, which recruit Raf to distinct membrane rafts.

From a functional standpoint, although all Raf proteins are serine/threonine kinases and capable of activating the MAPK cascade, they have distinct downstream phosphorylation targets and play unique roles in signaling. ${ }^{13}$ Their distinct roles are supported by Raf knockout studies, in which mice lacking each of the three Raf proteins have disparate phenotypes. ${ }^{113,114} B$-raf knockouts die in utero by day 12 , usually as a result of massive internal hemorrhage, whereas $A$-raf and $C$-raf knockouts die postpartum with extensive intestinal distension (A-raf knockout) or failure of lung maturation ( $C$-rafknockout). Additional support for the diverse functionality of Raf family members is provided by the disparate responses of B-Raf and C-Raf to identical stimuli, as well as the distinct messages that each isoform relays downstream to Rap1, which is a small GTPase that functions as both an activator and repressor of Raf. ${ }^{115}$ For example, Rap1mediated stimulation of B-Raf by cyclic adenosine monophosphate (cAMP) phosphorylates ERK, whereas stimulation of C-Raf inhibits ERK phosphorylation. ${ }^{115}$

\section{The Structure of Raf}

The structure of Raf consists of the following: (1) an amino terminus that contains the regulatory domain; (2) an activation loop; and (3) a carboxyl terminus that contains the kinase domain ${ }^{116-118}$ (Fig 4). All Raf kinases are composed of three conserved regions, CR1 (adjacent to the amino terminus), CR2, and CR3 (adjacent to the carboxyl terminus). The regulation of Raf kinase activity is a complex process involving phosphorylation of the regulatory and catalytic domains of the protein and both inter- and intramolecular interactions. The initial process of Raf activation involves the interaction of active GTP-bound Ras with the RBD of Raf and the adjacent zinc-binding cysteine-rich domain (CRD) of $\mathrm{CR} 1$, facilitating recruitment of Raf to the cell membrane for activation. ${ }^{78}$ The role of CR2, which is rich in serine and threonine residues, is less well defined; however, the phosphorylation of moieities within CR2 and various proteinprotein interactions involving CR2 also affect Raf localization and activation. ${ }^{89,119-121}$ Deletions of the amino-terminal regulatory domains CR1 and CR2, similar to $v$-Raf, are found in 
several types of human cancers with activating Raf mutations, suggesting that these domains negatively regulate Raf function. CR3, the catalytic domain of Raf, is also subject to regulation by phosphorylation.

\section{Regulation of Raf Kinase Activity}

General. The overlapping functional aspects of the three Raf isoforms have been elucidated by studies involving Raf knockout mice. In C-Raf knockouts, B-Raf can compensate for the loss of C-Raf in activating MEK in the MAPK pathway, but C-Raf knockouts are much more susceptible to apoptotic stimuli, despite the presence of A-Raf and B-Raf. ${ }^{122}$ With regard to differences in signaling between the Raf isoforms, A-Raf is a weaker activator of MEK than B-Raf or C-Raf. Furthermore, A-Raf can activate MEK1 only, whereas C-Raf activates both MEK1 and MEK2. ${ }^{123-125}$ As shown in Figure 3, Raf kinases are activated by Ras, other small GTPase regulatory proteins, and scaffolding proteins, and the magnitude and quality of downstream signaling are dependent on the integration of activating events and protein interactions.

C-Raf exists in the cytoplasm as a 300- to 500-kd protein complex. The complex consists of C-Raf, heat shock protein 90 (Hsp90), and the dimeric protein cofactor 143-3. 14-3-3 binds to two specific phosphoserine residues of C-Raf, which masks its kinase domain and inactivates the protein. The binding of Ras to C-Raf displaces the 14-3-3 dimer, rendering C-Raf accessible to dephosphorylation by protein phosphatase $2 \mathrm{~A} .{ }^{126}$ This action enables subsequent activation of C-Raf by mitogenic stimuli. The stability and function of C-Raf are also regulated by the phosphorylation status of C-Raf itself, the binding of C-Raf to Ras, and interactions between C-Raf and cellular lipids.

Activation by Ras and other small GTPases. The initial event in the activation of Raf is its recruitment to the inner surface of the cell membrane by the small GTPase Ras. The effector domain of GTP-bound Ras binds to C-Raf through the RBD and CRD in the CR1. Although binding to both sites is required for Raf activation, the most critical interaction is between Ras-GTP and the RBD. ${ }^{127}$ All Ras isoforms are capable of interacting with Raf, but K-Ras is the most potent activator, whereas N-Ras is much more efficient than H-Ras. ${ }^{128}$ The interaction between Ras and C-Raf alone is insufficient to activate C-Raf, but it serves to translocate C-Raf to the cell membrane where it can be activated.

The activation of B-Raf by Ras has been less well studied; however, the interacting amino acids in the Ras-Raf interface are identical for B-Raf and C-Raf. ${ }^{129,130}$ The association of Ras with B-Raf also translocates B-Raf to the cell membrane where it is activated. ${ }^{124}$ Interestingly, a membrane-free complex of B-Raf and 14-3-3 can be activated in vitro by recombinant Ras. This is in stark contrast to A-Raf and C-Raf, which must undergo a series of phosphorylation reactions on serine and tyrosine residues in the cell membrane and cannot be activated by Ras alone. ${ }^{124,130}$ Of the Raf isoforms, B-Raf is activated first, and on stimulation by Ras, it heterodimerizes with C-Raf, the significance of which is not known. ${ }^{94}$

Both B-Raf and C-Raf can bind to other small GTPases, most notably Rap $1 .{ }^{115,131,132}$ The effector domains of Rap1 and Ras are nearly identical, but activation of these proteins produces vastly different downstream effects. Furthermore, Rap1 mediates distinct effects after binding to various Raf isoforms. The B-Raf-Rap1 complex activates B-Raf, whereas the C-Raf-Rap1 interaction does not activate C-Raf and, in fact, may be inhibitory. ${ }^{115,132,133}$ This occurs because Rap1 binds to the CRD of C-Raf with higher affinity than Ras and excludes Ras from binding.

The Rho family of small GTPases, consisting of Rho, Rac, and cyclin-dependent kinase (Cdc) 42, regulate cytoskeletal organization during the cell cycle and also mediate Ras-induced activation of Raf, especially C-Raf. ${ }^{134-136}$ These GTPases do not directly bind to Raf but, instead, signal by activating downstream kinases. Rho signals by activating the serine/threonine protein kinases $\mathrm{N} 1$ and $\mathrm{N} 2$ and Rho-associated kinase 1, whereas Rac and Cdc42 signal through p21-activated kinase (PAK). ${ }^{134-136}$

Phosphorylation. Raf is principally activated by phosphorylation of specific amino acid residues as shown for each isoform in Figure 4. From an evolutionary standpoint, the Raf activation sites are highly conserved from yeast to humans. Several amino acids in Raf, particularly serine (S) 259 and S621, which bind 14-3-3 and maintain C-Raf in a closed auto-inhibited conformation, are phosphorylated in the basal state. ${ }^{137}$ On stimulation, Ras-GTP displaces 143-3 from S259, and C-Raf is translocated to the cell membrane, where it can be dephosphorylated at $\mathrm{S} 259$ by protein phosphatase 2A or other phosphatases. ${ }^{126}$ S259 also represents the site of inhibitory phosphorylation by $\mathrm{PKB} / \mathrm{Akt}$, PKA, and serum glucocorticoid-inducible kinase. ${ }^{121,138,139}$ Phosphorylation at S621 seems to have greater significance because mutations at this site inactivate Raf's kinase activity. Hence, a balance of phosphorylation and dephosphorylation is required to prime Raf in the basal state before stimulation by Ras or mitogens. ${ }^{137}$

Raf is also phosphorylated at other serine and threonine residues, the most important of which are S338 and tyrosine (Y) 341, which are situated adjacent to the C-Raf kinase domain. ${ }^{140}$ Phosphorylation of these residues relieves the inhibitory effects of the regulatory domain on the kinase domain. ${ }^{141}$ S338, which is the evolutionarily conserved PAK phosphorylation site that resides on the aminoterminal side of the kinase domain, is critical for Raf activation. ${ }^{134-136,140,142}$ This site is also phosphorylated in response to stimulation by growth factors, integrins, Ras, PAK1, and PAK3. ${ }^{78,136,143}$ The homologous site on B-Raf, S445, is constitutively phosphorylated, accounting for the higher basal activity of B-Raf. Ras presumably phosphorylates this site by activating PI3K. Activated mutants of Rac 
and Cdc42 are also capable of inducing phosphorylation of S338 by activating PAK. Y341 is phosphorylated by the Src family of non-RTKs, Janus kinase, and erythropoietin. ${ }^{85,92}$ The substitution of this tyrosine residue by aspartate in B-Raf may explain why B-Raf is fully inducible by Ras, whereas A-Raf and C-Raf require both Ras and Src for full activation. ${ }^{124}$ However, Ras-mediated recruitment of C-Raf to the cell membrane and Src activation are not the only steps involved in the activation of C-Raf.

A-Raf, which is structurally similar to C-Raf, is activated in a similar manner; however, the pertinent structural and activational aspects of B-Raf differ from those of A-Raf and C-Raf. Although the structural domains and phosphorylation sites of Raf proteins differ, the greater degree of phosphorylated amino acids in B-Raf confers a 15- to 20fold higher level of kinase activity in the basal state than either A-Raf or C-Raf, and B-Raf is therefore a much more robust activator of ERK phosphorylation. ${ }^{85,144,145}$ The differential splicing of B-raf may also account for the distinct kinase activity of the protein. In addition, the structures of several B-Raf mutants mimic the conformational changes unique to phosphorylated wild-type B-Raf, which may explain the ability of B-Raf mutants to activate ERK in the absence of stimulation.

Other interactions. In addition to phosphorylation events, the activation status of C-Raf is regulated by protein-protein and protein-lipid interactions. As shown in Figure 2, C-Raf interacts with a diverse array of scaffolding proteins (kinase suppressor of Ras and MEK partner-1), adaptor proteins (Bcl-2-associated athanogene-1), chaperone proteins (Hsp90 and Hsp70), substrates (retinoblastoma protein $[\mathrm{Rb}]$ ), lipids (phosphatidic acid, cholesterol-rich caveolae, and cytosolic lipid rafts), and cellular constituents, many of which, in turn, modulate its kinase activity. ${ }^{95}$

\section{Activation of Downstream Effectors by Raf}

Activated Raf principally propagates signaling by phosphorylating the two dual-specificity MAPKKs, MEK1 and MEK2 (also referred to as MKK1 and MKK2; Figs 1 and 2). ${ }^{75}$ The Raf isoforms are the best characterized MEK1 and MEK2 activators, and all Raf isoforms activate MEK1, whereas only B-Raf and C-Raf activate MEK2. MEK1 and MEK2 contain a proline-rich sequence that enables recognition and activation by Raf. ${ }^{125,146-153}$ This sequence, which is not present in other MAPKKs, may explain why Raf preferentially activates MEK1 and MEK2, whereas the dualspecificity p38 ${ }^{M A P K}$ kinases (MKK3 and MKK6) and JNK kinases (MKK4 and MKK7) phosphorylate p38 $8^{M A P K}$ and JNK, respectively. Although both A-Raf and C-Raf are capable of activating other signaling elements independent of MAPK pathway activation, such as nuclear factor-kappa $B$ $(\mathrm{NF}-\kappa \mathrm{B}), \mathrm{Rb}$, and $\mathrm{Bcl}-2, \mathrm{MEK} 1$ and MEK2 are the only known substrates for B-Raf. ${ }^{154-157}$ A consistent theme in studies on MEK/ERK activation by Raf is that B-Raf is far more potent at activating downstream kinases than either A-Raf or C-Raf. Several lines of evidence also indicate that B-Raf has a much higher affinity for its substrate than the other Raf isoforms and is 50-fold more potent at phosphorylating MEK1 and MEK2 than either A-Raf or C-Raf. ${ }^{125,158}$

The respective downstream substrates of MEK1 and MEK2 are ERK1 ( $\left.444^{M A P K}\right)$ and ERK2 $\left(\mathrm{p} 42^{M A P K}\right)$, which are translocated to the nucleus where they ultimately induce an array of cytoplasmic and nuclear regulatory proteins. ${ }^{50,159-162}$ Effectors include the nuclear transcription factors Elk-1, Fos, Jun, AP-1, and Myc, which regulate genes encoding proteins that play key roles in proliferation, angiogenesis, metastasis, and resistance to anticancer therapeutics. ${ }^{51}$ As a result, cell cycle regulators, such as cyclins D1 and E and Cdc activator 25 phosphatase, are positively regulated, ${ }^{163,164}$ whereas p2 $7^{\text {kip-1 }}$ and other inhibitors of cyclin-dependent kinases (cdk) are negatively regulated. ${ }^{51}$ These actions favor progression through cell cycle checkpoints, aberrant growth, dedifferentiation, and cell survival.

C-Raf activates other cellular effectors, but the extent of the interdependence of these actions on MEK1 and MEK2 is not clear. For example, C-Raf activation regulates cytoskeleton formation by modulating the polymerization status of vimentin. ${ }^{165}$ Cell survival signaling is also regulated by $\mathrm{C}-\mathrm{Raf}$, which induces phosphorylation of $\mathrm{I} \kappa \mathrm{B}$ in the NF- $\kappa \mathrm{B}-\mathrm{I} \kappa \mathrm{B}$ complex. This action releases activated $\mathrm{NF}-\kappa \mathrm{B}$, which is then translocated to the nucleus where it mediates transcription of antiapoptotic factors. ${ }^{155,166}$ Other antiapoptotic effects of C-Raf are mediated by a mitochondrial pool of the protein, which, on stimulation, localizes to the mitochondrial membrane where the protein interacts with and phosphorylates Bcl-2, Bcl-2-associated athanogene, and other pro-apoptotic regulators, abrogating their pro-apoptotic effects. ${ }^{157,167}$ The antiapoptotic effects of C-Raf are also mediated through the ankyrin-repeat protein Tvl-1 and apoptosis signal-regulated kinase- $1 .{ }^{166,168,169}$ In addition, C-Raf phosphorylates Rb, p53, Cdc25, and other cell cycle regulatory proteins in metaphase. ${ }^{156,170,171}$ Lastly, $\mathrm{C}$-Raf induces transcription of the multidrug resistance gene $m d r-1$, and its activation has been associated with multidrug resistance. ${ }^{172}$ In summary, Raf mediates essential cellular processes that signal proliferation, survival, and drug resistance.

\section{RAF MUTATIONS IN HUMAN CANCER}

\section{General}

Constitutively active mutant Raf proteins are predominately a result of point (missense) mutations, deletions, amplification, and rearrangements of raf. ${ }^{173-176}$ Such genetic alterations have been identified in malignant melanoma, hematopoietic cancers, and cancers of the thyroid, breast, kidney, liver, larynx, biliary tract, and other organs, as shown in 
Table 1. ${ }^{173-176}$ Although initial efforts at identifying raf mutations in human cancer focused on C-raf, the advent of high-throughput gene sequencing led to the identification of activating B-raf mutations as the predominant genetic aberrations. ${ }^{11,122,145,177}$

\section{B-raf Mutations}

Recently, a sequence screen of 923 cancer samples for genes mutated in human cancers identified somatic mutations in a notable proportion of tumor samples. ${ }^{9}$ Somatic B-raf mutations were demonstrated in $60 \%$ to $70 \%$ of malignant melanomas and in moderate to high rates in carcinomas of the colon, ovary, and thyroid (papillary), implicating activating oncogenic $B$-raf mutations as critical promoters of these malignancies. ${ }^{9,14-17}$ Furthermore, somatic B-raf mutations were found, albeit at lower rates, in glioma, sarcoma, non-Hodgkin's lymphoma, acute myeloid leukemia, and carcinomas of the breast, lung, and liver. Interestingly, $C$-raf mutations were not identified in a series of 545 cancer samples, including melanomas and carcinomas of the colon, ovary, and lung. ${ }^{9}$

Sequence analysis of $B$-raf in human cancer has identified more than 30 single-site missense mutations, principally encoding amino acids in the kinase domain of B-Raf, whereas the constitutive activity and transforming potential of C-Raf result from loss of the auto-inhibitory aminoterminal region, as well as gene rearrangements. ${ }^{6,175,176}$ Most $B$-raf mutations are caused by thymidine-to-adenine transversions at nucleotide position 1796 in exon 11 or 15, which encode a valine-to-glutamic acid substitution at amino acid 599 ( $\left.{ }^{\mathrm{V} 99 \mathrm{E}} \mathrm{B}-\mathrm{Raf}\right)$ in the activation segment (kinase domain) of the protein. Interestingly, structural changes in the activation segment as a result of the insertion of an acidic residue close to a site of regulated phosphorylation mimic phosphorylated B-Raf. ${ }^{\text {V599E }}$ B-Raf possesses the hallmarks of a conventional oncogene because the kinase activity of its encoded protein is greatly elevated; it constitutively stimulates ERK in vivo in the absence of Ras activation; and it transforms NIH3T3 cells. ${ }^{144}$ Furthermore, the basal kinase activity of ${ }^{\mathrm{V} 999 \mathrm{E}} \mathrm{B}$-Raf is 12.5 -fold higher than that of wild-type B-Raf, and its responsiveness to stimulation by oncogenic H-Ras is diminished. Furthermore, the transforming capacity of ${ }^{\mathrm{V} 599 \mathrm{E}} \mathrm{B}-\mathrm{Raf}$ in NIH3T3 cells is 667-fold more efficient than that of wild-type B-Raf, whereas the equivalent mutation introduced into C-Raf (V492E) confers 10-fold lower kinase activity and transforming capacity. ${ }^{85}$

The discovery of B-raf mutations in $60 \%$ to $70 \%$ of malignant melanomas is surprising because early studies attributed the hyperactivation of the Raf/MEK/ERK module of the MAPK pathway in melanoma to an abundance of autocrine and paracrine growth factors. Interestingly, B-raf mutations are not found in uveal melanoma, which differs from cutaneous melanoma in that abnormalities of chro- mosome 6 are found only in uveal melanoma, suggesting that there are distinct pathways for melanoma formation. ${ }^{178,179}$ Further studies evaluating the function of ${ }^{\mathrm{V} 599 \mathrm{E}} \mathrm{B}$-Raf in benign and dysplastic nevi may yield important information about the type and timing of events required for tumorigenesis. Interestingly, the ${ }^{\mathrm{V} 599 \mathrm{E}} \mathrm{B}-\mathrm{Raf}$ allele is found in as many as $80 \%$ of benign nevi, suggesting a role for oncogenic B-raf in nevus formation and melanoma initiation. ${ }^{180}$ However, there is no direct evidence that benign nevi harboring ${ }^{\mathrm{V} 599 \mathrm{E}} \mathrm{B}$-Raf progress to malignancy, and most cases may actually represent terminally differentiated lesions analogous to nondysplastic colorectal aberrant crypt foci that harbor $K$-ras mutations in the absence of adenomatous polyposis coli (APC) mutations. APC mutations are generally considered to be of low malignant potential, whereas $K$-ras mutations that arise after $A P C$ mutations promote colorectal tumor progression. ${ }^{181,182}$ Further studies are also needed to determine whether the prevalence of $B$-raf mutations in melanoma relates to the site of the primary tumor, sun exposure, and radiation damage. Similar findings have been noted in the setting of papillary thyroid carcinoma, in which up to $69 \%$ of tumors harbor ${ }^{\mathrm{V} 599 \mathrm{E}} \mathrm{B}-\mathrm{Raf}$, whereas benign thyroid tumors and both follicular and medullary thyroid carcinomas do not. ${ }^{18,19}$ It is notable that $B$-raf mutations are common in melanoma and thyroid cancers and that both melanocyte and thymocyte growth is positively regulated by cAMP. Interestingly, B-Raf is thought to be the key Raf isoform that transduces cAMP-dependent growth signals in both cell types, which may account for their vulnerability to transformation by activating mutations of this kinase. ${ }^{183,184}$

Analysis of other much less common oncogenic B-Raf mutants, most of which cluster adjacent to valine 599 or in the G loop ATP-binding region, suggest that the mutated proteins stimulate kinase activity in a manner similar to ${ }^{\mathrm{V} 599 \mathrm{E}} \mathrm{B}$-Raf. ${ }^{9}$ Nevertheless, it is intriguing that several of these mutations involve highly conserved or invariant residues in the catalytic domain, which are required by other kinases for optimal activity. This raises the question of how these mutants promote tumorigenesis. ${ }^{8,9,185}$ It should also be noted that $B$-raf mutations outside the kinase domain have been identified, and other mutations will likely be identified as the gene is sequenced in other types of malignancies. ${ }^{11}$

Mutations of B-raf and ras are essentially mutually exclusive, implying that these genes belong to the oncogenic signaling pathway. Fewer than $1 \%$ of cancers with $B$-raf mutations have simultaneous ras mutations, and of the $1 \%$ that have mutations of both genes, the B-raf mutations are almost never ${ }^{\mathrm{V} 599 \mathrm{E}} \mathrm{B}$-Raf. ${ }^{8,9,14}$ In colorectal carcinoma, both genes are mutated at high frequencies in the same types of premalignant lesions and at the same stages in the transition from adenoma to carcinoma. ${ }^{8,14} \mathrm{~A}$ strong association exists between mismatch repair deficiency and the presence of the mutant ${ }^{\mathrm{V} 599 \mathrm{E}} \mathrm{B}-\mathrm{Raf}$ protein in colorectal carcinoma, which 
may be a result of the underlying DNA repair defect. ${ }^{14}$ Further reflecting the redundancy of the MAPK pathway, a high fraction of papillary thyroid cancers harbor either ${ }^{V 599 E} B$-Raf, mutant $K$-ras, or mutant RET. ${ }^{9,20}$ Harboring more than one mutation is quite rare, although a moderate fraction of low-grade ovarian tumors harbor either ${ }^{V 599 E} B$ Raf or mutant $K$-ras. ${ }^{9,20}$ This finding may represent a unique paradigm of human tumorigenesis through mutations of these signaling proteins that lie in tandem. ${ }^{8,9}$ However, concomitant ras mutations have been identified in cancers that harbor uncommon B-raf mutations in the G loop region, suggesting that there may be differences in molecular pathways used by distinct mutant B-Raf proteins. ${ }^{9}$

\section{C-raf Mutations}

In contrast to $B$-raf mutations, no underlying genetic mechanisms predominate in human cancers that harbor $C$-raf mutations. Several types of genetic alterations, particularly gene rearrangements, have been demonstrated in human cancers sampled from patients with non-small-cell lung carcinoma and T-cell lymphoma harboring C-raf mutations. ${ }^{10}$ In addition, constitutively active C-Raf has been associated with site-specific $C$-raf mutations, and a structurally aberrant C-Raf protein that is truncated in its amino-terminal regulatory domain has been identified in tumor samples from patients with carcinomas (kidney, lung [small cell], liver, and pancreas), sarcomas (soft tissue and bone), and CNS malignancies (glioma, glioblastoma, and ependymoma). ${ }^{6,186,187}$ However, neither specific genetic nor structural aberrations have been identified in a sizeable proportion of human cancers in which C-Raf is activated in the absence of upstream Ras activation. ${ }^{6,175,177}$

\section{THERAPEUTIC STRATEGIES TARGETING RAF}

Given the high proportion of cancers with constitutively activated Raf, Ras mutations, or growth factor hyperactivity, which result in increased signaling through Raf, Raf is an ideal target for therapeutic development. Although there have been many attempts to develop therapeutics against Raf, most efforts have been directed at C-Raf rather than B-Raf. To decrease Raf production and inhibit its activation, antisense oligonucleotides (ASONs), small-molecule kinase inhibitors, and dominant interfering DNA constructs are being developed. In addition, other therapeutics that indirectly target Raf include inhibitors of chaperone proteins (eg, geldanamycin analogs), which destabilize Raf, and histone deacetylase inhibitors, which reduces raf expression. ${ }^{188}$

\section{ISIS 5132 (CGP 69846A): AN ASON INHIBITOR OF C-RAF}

The specificity of nucleotide base pairing provides the rationale for using ASONs as therapeutics against Raf. ${ }^{189,190}$ This approach relies on the intracellular uptake of short synthetic ASONs that are complementary to Raf mRNA by mechanisms that have not been clearly elucidated. The ASON then hybridizes with its cognate mRNA, leading to RNAase $\mathrm{H}-$ mediated degradation of the complex. Alternatively, the ASON can sterically inhibit translation, which reduces synthesis of the encoded protein.

ISIS 5132 (CGP 69846A; ISIS Pharmaceuticals Inc, Carlsbad, CA) is a 20-base phosphorothioate ASON designed to hybridize to the $3^{\prime}$ untranslated sequence of $C$-raf. ${ }^{191}$ Binding induces degradation of the C-Raf mRNA, which, in turn, decreases synthesis of C-Raf in a concentration-dependent manner. ${ }^{192}$ The 50\% inhibitory concentration $\left(\mathrm{IC}_{50}\right.$ ) value for both tumor proliferation and C-Raf expression is approximately $100 \mathrm{nmol} / \mathrm{L} .{ }^{192}$ Furthermore, treatment of mice bearing human lung and breast cancer xenografts produces impressive decrements in C-Raf, as well as antitumor activity. ${ }^{191}$ In other models, ISIS 5132 decreases C-Raf expression and enhances sensitivity to both cytotoxics and radiation. ${ }^{193}$ The phosphorothioate backbone of ISIS 5132 was engineered to confer resistance to digestive nucleases, which is manifested by plasma half-life values ranging from 30 to 85 minutes and extensive tissue distribution in mice. ${ }^{194-196}$

The feasibility of administering ISIS 5132 was explored in patients with advanced solid neoplasms on the following schedules: (1) 21-day continuous intravenous (IV) infusion (CIVI) every 28 days; (2) 2-hour IV infusion thrice weekly for 3 weeks every 28 days; and (3) 24-hour IV infusion weekly for 3 weeks every 28 days. ${ }^{197-199}$ The principal toxicities were fever and malaise. Thrombocytopenia and anemia, which were typically moderate in severity, brief, and not cumulative, were also noted. Transient prolongation of the activated partial thromboplastin time and activation of the alternate complement pathway, which have been attributed to the phosphorothioate backbone of ISIS 5132, occurred in a dose-dependent manner. Dose-dependent elevations of the compliment component $\mathrm{C} 3 \mathrm{a}$, but not $\mathrm{Bb}$ or $\mathrm{C} 5 \mathrm{a}$, were noted. Although maximum tolerated doses were not clearly defined in the first two studies, plasma concentrations of intact ISIS 5132 achieved at the highest doses $(6$ and $4 \mathrm{mg} / \mathrm{kg} / \mathrm{d})$ exceeded $\mathrm{IC}_{50}$ values derived in vitro and were known to activate the alternate complement pathway in monkeys. ${ }^{198}$ In the third study, an unacceptably high incidence of intolerable toxicities, particularly Coombs hemolytic anemia and acute renal insufficiency, was noted in patients treated at doses greater than $24 \mathrm{mg} /$ $\mathrm{kg} / \mathrm{wk}$. The toxicities of ISIS 5132 were similar to those of other ASONs and, therefore, should not be interpreted as being related to target inhibition. Although several patients experienced protracted periods of stable disease, major tumor regression did not occur. C-raf mRNA levels in peripheral-blood mononuclear cells were consistently suppressed in patients receiving ISIS 5132 as a 2-hour IV 
infusion thrice weekly for 3 weeks, but suppression of $C$-raf mRNA was not detected on the schedule of 24-hour CIVI weekly for 3 weeks every 28 days and not evaluated in the study of ISIS 5132 as a 21-day CIVI.

The antitumor activity of ISIS 5132 was evaluated in phase II studies in patients with advanced colorectal (15 patients, no prior treatment for metastatic disease), hormonerefractory prostate (16 patients, no prior chemotherapy), ovarian (22 patients, one to two prior systemic therapies), small-cell lung (four patients, one prior therapy), and nonsmall-cell lung (18 patients, no prior therapies) carcinomas. ${ }^{200-203}$ Stable disease lasting 2.5 to 5.5 months was the best response in a sizeable proportion of patients, but there were no major tumor regressions. Nonetheless, these disappointing results should not diminish the potential importance of Raf as a therapeutic target because several alternative hypotheses, including the lack of validation of ASON technology as a platform that can confer robust anticancer activity and lack of documentation of raf mutational status in these clinical studies, may explain these results.

\section{Small-Molecule Inhibitors of Raf Kinase}

The identification of nearly 500 kinases that can be classified into at least 20 families based on structural homology and recent successes with kinase inhibitors have produced bountiful opportunities for small-molecule inhibitors of Raf kinase. ${ }^{185}$ The elucidation of the crystalline structure of the ATP-binding domain of Raf has even further brightened these prospects. ${ }^{204,205}$ Several classes of small molecules are currently being optimized from both mechanistic and pharmaceutical standpoints. In addition to blocking Raf kinase, small molecules directed at Raf also inhibit a wide range of other kinases by virtue of structural homology between the kinase families. Although it may be desirable for smallmolecule therapeutics to impart inhibitory effects on multiple critical signaling pathways, these multifunctional aspects may also impart greater toxicity. Of the small-molecule Raf inhibitors in development, sorafenib (BAY 43-9006; Bayer Corporation Pharmaceutical Division, New Haven, CT; and Onyx Pharmaceuticals, Inc, Richmond, CA; Fig 5) is the furthest along.

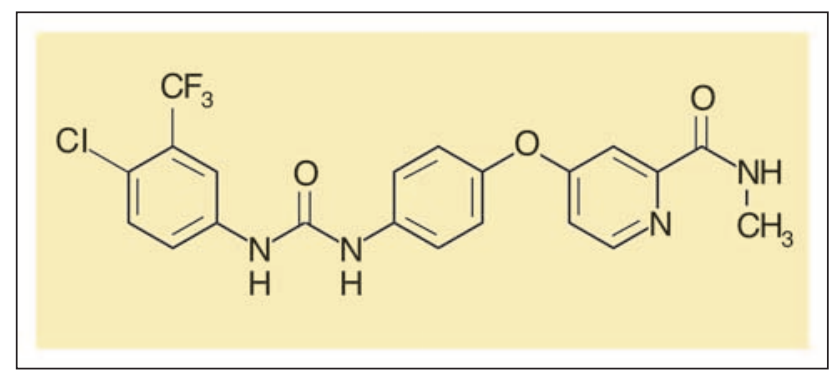

Fig 5. Chemical structure of sorafenib (BAY 43-9006)

\section{Sorafenib (BAY 43-9006): Mechanism of Action and Preclinical Results}

The bi-aryl urea sorafenib (4-\{4-[3-(4-chloro-3trifluoromethyl-phenyl)-ureido]-phenoxyl\}-pyridine-2carboxylic acidmethylamide-4-methylbenzene-sulfonate; BAY 43-9006) is the first molecule of its class to undergo clinical development. Originally identified by high-throughput screening of small molecules against C-Raf kinase, sorafenib was found to be a potent competitive inhibitor of ATP binding in the catalytic domains of C-Raf, wild-type B-Raf, and ${ }^{{ }^{~} 599 \mathrm{E}} \mathrm{B}$-Raf mutant. As shown in Table 2, the $\mathrm{IC}_{50}$ values of sorafenib against C-Raf, wild-type B-Raf, and the ${ }^{\mathrm{V} 599 \mathrm{E}} \mathrm{B}-\mathrm{Raf}$ mutant in a biochemical assay are in the low nanomolar range, whereas sorafenib does not inhibit MEK1, ERK1, erbB1, or erbB2. ${ }^{206}$ Sorafenib potently inhibited activation of the MAPK pathway and ERK phosphorylation in human cancer cell lines, irrespective of whether they harbored $K$-ras mutations, ${ }^{V 599 E} B$-Raf, or both. ${ }^{207}$ Further characterization of sorafenib in biochemical assays showed potent inhibition of pertinent RTKs involved in tumor progression and angiogenesis, including human and murine vascular endothelial growth factor receptor (VEGFR) -2, VEGFR-3, platelet-derived growth factor receptor-beta (PDGFR- $\beta$ ), Flt-3, c-Kit, p38 $\alpha$, and fibroblast growth factor receptor-1 (Table 2). In contrast, erbB1, insulin-like growth factor-1, c-met, and erbB2 RTKs were not inhibited. The kinase activities of PKA, $\mathrm{PKB}, \mathrm{PKC} \alpha$, PKC $\gamma$, cdk1/cyclin B, and pim-1 were also insensitive. ${ }^{208}$ Furthermore, sorafenib inhibited various nonkinase

\begin{tabular}{|c|c|}
\hline Biochemical Assay & $\mathrm{IC}_{50}(\mathrm{nmol} / \mathrm{L})$ \\
\hline C-Raf & 6 \\
\hline B-Raf, wild-type & 22 \\
\hline B-Raf mutant, V599E & 38 \\
\hline VEGFR2 & 90 \\
\hline mVEGFR-2 & 6 \\
\hline mVEGFR-3 & 12 \\
\hline mPDGFR- $\beta$ & 57 \\
\hline Flt-3 & 58 \\
\hline c-Kit & 68 \\
\hline p38 $\alpha$ & 38 \\
\hline FGFR-1 & 580 \\
\hline $\begin{array}{l}\text { EGFR, HER-2, ERK1, MEK1, IGFR-1, c-met, } \\
\text { c-yes, PKB, PKA, cdk1/cyclin B, PKC } \alpha \text {, } \\
\text { PKC } \gamma \text {, pim- } 1\end{array}$ & $>10,000$ \\
\hline \multicolumn{2}{|c|}{$\begin{array}{l}\text { Abbreviations: cdk, cyclin-dependent kinase; EGFR, epidermal growth } \\
\text { factor receptor; ERK, extracellular signal-regulated kinase; FGFR-1, fibro- } \\
\text { blast growth factor receptor-1; HER-2, human epidermal growth factor } \\
\text { receptor } 2 \text {; IC } \mathrm{C}_{50} \text {, concentration of sorafenib that inhibits the kinase } \\
\text { activity by } 50 \% \text {; IGFR, insulin-like growth factor receptor; mPDGFR, } \\
\text { mouse platelet-derived growth factor receptor; PKA, protein kinase A; } \\
\text { PKB, protein kinase } B \text {; PKC, protein kinase C; m, murine; MEK1, } \\
\text { mitogen-activated protein kinase kinase } 1 \text {; VEGFR, vascular endothelial } \\
\text { growth factor receptor. }\end{array}$} \\
\hline
\end{tabular}


targets, including adenosine A3, dopamine D1, and muscarine $\mathrm{M} 3$, albeit at much higher (micromolar) concentrations than kinase targets. ${ }^{209}$ In cellular assays, sorafenib reduced basal phosphorylation of the MAPK pathway in a panel of human breast, melanoma, pancreatic, and colon cancer cell lines expressing either mutant K-Ras, mutant B-Raf, or wildtype Ras or Raf. Interestingly, several non-small-cell lung cancer cell lines expressing mutant $K$-ras were resistant, presumably because Raf-independent activation of MEK is operative in these cells. ${ }^{208,210}$ In other cell-based assays, sorafenib inhibited phosphorylation of several pro-angiogenic RTKs, including both human VEGFR-2 and murine VEGFR-2, murine VEGFR-3, PDGFR- $\beta$, and Flt- $3 .{ }^{208,210}$ In nude mice bearing human xenografts derived from melanoma and colon, pancreas, breast, and lung carcinomas, sorafenib treatment resulted in a high level of tumor growth inhibition without appreciable toxicity. ${ }^{206}$ Most early evaluations used the HCT116 human colon xenograft because its tumorigenicity depends on K-Ras activation. Extending the duration of sorafenib treatment attained protracted antitumor efficacy, even when treatment was initiated in settings of high tumor burden. Significant growth inhibition was noted after treatment of well-established human xenografts with $B$-raf mutations (HT29, Colo205, and DLD-1 colon), K-ras mutations (NIH-H460 and A459 lung; MiaPaCa pancreas), and both $K$-ras and B-raf mutations (MDA-MB-231 breast) with sorafenib at doses of 7.5 to $60 \mathrm{mg} / \mathrm{kg}$ daily for 9 days. B-raf-mutated MDA-MB-231 breast cancer xenografts, which were reduced in size by $42 \%$, on average, after only 9 days of treatment with $30 \mathrm{mg} / \mathrm{kg}$ of sorafenib, were the most sensitive. ${ }^{208,210}$ Relevant activity against the human SKOV-3 ovarian xenograft that harbors wild-type Ras but overexpresses both erbB1 and erbB2 was also noted.

Concurrent with the demonstration that sorafenib is efficacious in a molecularly diverse range of human tumor xenografts, translational studies have demonstrated inhibition of the MAPK pathway after 5 days of sorafenib treatment of HT-29, DLD-1, HCT-116, and MDA-MB-231, but not Colo-205 xenografts. In the Colo-205 tumors, in which concurrent assessments of vascular effects were performed, tumor neovascularization was reduced dramatically. The cumulative results of these studies suggest that sorafenib inhibits tumor progression by blocking cellular proliferation that is dependent on activation of the MAPK pathway and/or inhibiting tumor angiogenesis through VEGFR-2, VEGFR-3, and/or PDGFR- $\beta$. Recent studies suggest C-Raf inhibition may also promote the death of endothelial cells as a result of their specific requirements for stimulation by VEGFR-2. ${ }^{211}$ The results indicate that sorafenib is efficacious not only against human tumors with ras and/or raf mutations, but also against tumors that overexpress growth factor receptors that signal through Ras and the Raf/MEK/ ERK module. However, it is important to note that the relative potency of sorafenib against various kinases, partic- ularly VEGF, must be considered in assessing the value of sorafenib as a Raf kinase inhibitor, as well as in drawing conclusions about the value of Raf kinase as a molecular target against cancer.

Favorable cytotoxic effects were noted after treatment of a broad spectrum of human cancer cell lines and xenografts harboring both wild-type and mutated forms of ras or raf with sorafenib and either fluorouracil, paclitaxel, gemcitabine, gefitinib, vinorelbine, doxorubicin, irinotecan, or its active SN-38 metabolite. ${ }^{212}$ Treatment of human tumor xenografts with sorafenib plus paclitaxel, irinotecan, gemcitabine, or cisplatin did not enhance the toxicity or diminish the activities of the therapeutics.

Pharmacokinetic studies in rodents and dogs have demonstrated that sorafenib clearance is much lower than normal liver plasma flow. Its low steady-state volume of distribution (approximately 0.7 to $0.93 \mathrm{~L} / \mathrm{kg}$ ) suggests that tissue affinity is low and plasma protein binding is high (mean free fraction, 1.2\% [human] to 2.5\% [mouse]). The pharmacokinetics in mice are dose proportional over a biologically relevant dosing range, and tissue concentrations are several fold higher than IC $_{50}$ values in vitro. ${ }^{206,208,213} \mathrm{At}$ higher doses, drug exposure increases disproportionately, possibly because of saturation of gastrointestinal absorption. Autoradiographic studies have revealed homogeneous drug distribution to peripheral tissues and modest penetration across the blood-brain barrier. The mean terminal half-life ranges from 6 to 7 hours. In rodents, oral bioavailability is high (approximately 79\%). Drug disposition is principally by CYP3A4 metabolism, followed by biliary and fecal excretion (approximately 90\%). CYP1A, CYP2C9, CYP2C19, and CYP3A are not induced after incubating drug with microsomal extracts from human hepatocytes. However, in vitro metabolism studies in human systems indicate extensive metabolism by CYP3A, and early clinical data indicate that disposition is principally by hepatic metabolism and fecal excretion. Sorafenib is a modest inhibitor of CYP2B6, CYP2C8, CYP2C9, CYP2C19, CYP2D6, and CYP3A4, and the propensity for interactions between sorafenib and drugs that inhibit and induce P-450 systems exists.

In rodents and dogs, sorafenib is well tolerated. Principal toxicities include emesis, diarrhea, and transaminase elevations. Histopathologic studies have revealed doserelated degenerative changes in the liver, stomach, duodenum, pancreas, kidneys, heart, testes, and ovaries and regenerative changes in the liver, pancreas, duodenum, and kidneys. Hypocellularity and necrosis of hematopoietic and lymphoid tissues and unusual findings involving the teeth and growth plate of the femur have been noted.

\section{Clinical Evaluations}

Phase I studies. Phase I end points were evaluated in patients with advanced solid malignancies in studies of the 
following daily oral schedules: (1) 7 days every 15 days; (2) 21 days every 28 days; (3) 28 days every 35 days; and (4) continuous treatment. The principal dose-related toxicities were diarrhea, vomiting, skin rash, fatigue, hypertension, and palmar-plantar erythrodysesthesia (hand-foot syndrome). Hand-foot syndrome was characterized by desquamation and discomfort of the digits, all of which were reversible. Clinically relevant elevations in serum amylase and lipase and both lymphopenia and anemia were uncommon. The incidences of intolerable toxicities, particularly diarrhea and hand-foot syndrome, were unacceptably high at sorafenib doses exceeding $400 \mathrm{mg}$ twice daily on a continuous schedule, which was recommended for phase II trials. Tumor regression was noted on several schedules, particularly when doses exceeded $200 \mathrm{mg}$ twice daily. One patient each with hepatocellular carcinoma and renal cell carcinoma (RCC) had partial responses, whereas tumor regressions of lesser magnitude occurred in patients with RCC and colorectal and ovarian carcinomas. Furthermore, approximately $50 \%$ of patients with colorectal, ovarian, hepatocellular, renal, and breast carcinomas had stable disease as their best response. ${ }^{214}$ Pharmacokinetic studies revealed dose proportionality up to $600 \mathrm{mg}$ twice daily and high interpatient variability. Steady-state was achieved by 7 days, and terminal half-life values ranged from 30 to 45 hours. ERK1/2 phosphorylation in $\mathrm{CD}^{+}$peripheral-blood mononuclear cells was inhibited. ${ }^{215,216}$

Disease-directed studies. The principal paradigm adopted for disease-directed evaluations of sorafenib represents a radical departure from traditional phase II approaches. Although phase II studies are being performed in malignancies of high interest, the principal disease-directed evaluation strategy was a randomized discontinuation trial. This unorthodox approach was undertaken because the predominant clinical benefit of the agent, particularly in patients whose tumors were not screened for molecular aberrations known to increase the probability of responding, was projected to be increased progression-free survival (PFS), which was also the principal beneficial effect in preclinical studies. In addition, because sorafenib inhibits multiple kinases, the use of any empiric screening and/or enrichment strategy, as well as any particular malignancy, could produce false-negative results. In contrast to randomized phase II studies, which lack sufficient statistical power to discern small to moderate, albeit relevant, differences between treatments, the randomized discontinuation study is designed so that there is an initial process of natural enrichment of the study population with patients who may have experienced benefit to treatment before patients are randomly assigned to either continue or discontinue drug treatment. ${ }^{217}$

The randomized discontinuation study is felt to be ideal for sorafenib and agents whose main benefit is expected to be tumor growth delay, which is not readily detected in nonrandomized studies. At the end of an initial lead-in phase, in which all patients receive the study drug, patients who experience a relevant degree of tumor growth are removed from the study. This weeding out process enriches the study population with patients who will most likely benefit from further treatment, thereby increasing the probability that the randomization step will be more efficient at detecting tumor growth inhibition related to drug. In essence, the lead-in period may furnish data about the inherent potential of the agent to induce tumor regression and can suffice as multiple phase II studies, each of which can be sized in real time to provide a requisite level of statistical power. At the end of the lead in period, patients whose tumors have not progressed are randomly assigned to either continue or discontinue treatment, ideally in a double-blinded, placebo-controlled fashion. The natural selection or enrichment of the population before random assignment increases the efficiency of the trial, with as few as $20 \%$ of the standard number of randomly assigned patients. Nonetheless, a shortcoming of this approach relates to its inability to precisely quantify the magnitude of antitumor activity. However, if there is a clear difference in PFS between the randomly assigned arms, conclusions can still be generated about the general activity of the agent. Nevertheless, if the results meet a sufficient level of interest, resourceintensive phase III studies may ensue.

The randomized discontinuation study, as depicted in Figure 6, was designed to discern differences in PFS between patients treated with either sorafenib or placebo in the randomization period. The randomization stage was sized to discern PFS in patients with colorectal carcinoma, which frequently harbors ras mutations, although patients with many tumor types were enrolled. At the end of the 12-week period, in which all patients received sorafenib $400 \mathrm{mg}$ twice daily, patients whose target lesions had increased in excess of $25 \%$ were taken off study. Because of concerns about randomly assigning patients who had potentially benefited from treatment, patients whose target lesions had regressed by greater than $25 \%$ were not randomly assigned and, instead, continued treatment until disease progression. $\mathrm{Pa}$ tients who experienced neither objective benefit of this magnitude nor disease progression were randomly assigned to either continue treatment with sorafenib or placebo. Because PFS was the primary end point in the randomization phase, placebo-treated patients who experienced progressive disease could be re-treated with sorafenib.

Patient accrual ended in January 2004, with 484 patients accrued at a rate of 36 patients per month at only five institutions in the United States and Europe. Of these, 408 patients were the focus of a recent report. ${ }^{218}$ Tumor regression was noted in previously treated patients with advanced melanoma, sarcoma, RCC, and colorectal, thyroid, and pancreatic cancers. Most colorectal carcinoma patients treated with sorafenib developed disease progression before random assignment. RCC emerged as a central focus of the 


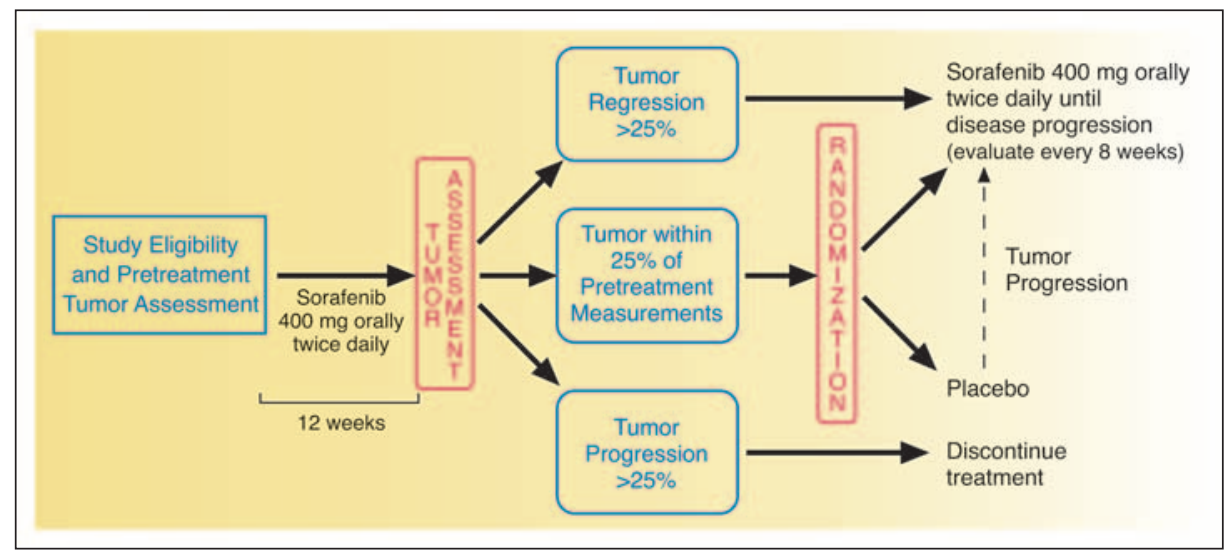

Fig 6. Schema of the randomized discontinuation trial with sorafenib (BAY 43-9006).

study, and the accrual targets for RCC were reset higher as the activity of sorafenib in RCC became increasingly evident. In the run-in phase, 202 patients with RCC were treated with sorafenib and were the focus of a recent report in May 2005. ${ }^{219}$ At 12 weeks, 144 patients (71\%) experienced tumor shrinkage or disease stabilization. Independently confirmed tumor shrinkage of $\geq 25 \%$ (partial response) was noted in eight $(4 \%)$ of these patients. A total of 65 patients were entered onto the randomization phase, of whom 32 were treated with sorafenib and the rest received placebo. Sixteen patients (50\%) in the sorafenib arm were progression free at 12 weeks postrandomization, compared with six patients $(18 \%)$ in the blacebo arm $(P=.0077)$. The median progression-free survival from randomization in the two arms was 24 weeks and 6 weeks, respectively $(P=.0087)$. The unique design of this study served the broad mechanism of action of this promiscuous tyrosine kinase inhibitor, providing a sufficient level of flexibility to evaluate a wide range of end points and tumor types. The intriguing results in patients with RCC provided the basis for a phase III study, in which 800 patients with unresectable and/or measurable RCC who have received at least one prior systemic therapy are being randomly assigned to treatment with either sorafenib or placebo. The primary and secondary end points were overall survival and progression free survival, respectively. A total of 905 patients were randomly assigned, of whom 769 patients were the focus of a recent report. $^{220}$ Three hundred eighty-four patients were randomly assigned to the sorafenib arm, and the rest to the placebo arm. An independent response assessment was performed in 574 patients. Seven partial responses $(2 \%)$ were noted in the sorafenib arm compared with none in the placebo arm. Disease stabilization was seen in 261 (78\%) versus $186(55 \%)$ patients in the sorafenib and placebo arms, respectively, and disease progression was noted in 29 (9\%) versus $102(30 \%)$ patients, respectively. The median progression-free survival for patients in the sorafenib arm was 24 weeks, compared with 12 weeks in the placebo arm (hazard ratio $=0.44 ; P=.000001$ ). The substantial benefit due to sorafenib was apparent across all patient subgroups. Because of the magnitude of the benefit noted upon analysis, treatment unblinding was performed, and patients randomly assigned to placebo were allowed to cross over to sorafenib treatment.

There was considerable interest in the melanoma patients who participated in the randomized discontinuation study based on the high incidence of $B$-raf mutations in melanoma. ${ }^{218}$ In the June 2004 report that focused on the first 20 patients enrolled, five patients developed cutaneous toxicity of grade 3 severity, and two patients developed hypertension that required intervention. ${ }^{221}$ Of 19 patients whose disease had been evaluated, 15 patients developed progressive disease before or at the planned 12-week assessment, whereas one patient had a partial response, and three patients had stable disease. Although a complete survey of $B$-raf mutations was not available for the June 2004 report, the negligible antitumor activity in a malignancy with a $60 \%$ to $70 \%$ incidence of constitutive B-raf mutations implies that sorafenib alone on the dose schedule evaluated lacks sufficient activity at inhibiting B-Raf kinase. Phase II studies are also ongoing in advanced hepatocellular and nonsmall-cell lung carcinomas and other malignancies.

Combination studies. The feasibility of administering sorafenib with various other agents is being evaluated in early clinical evaluations. Flaherty et al, ${ }^{222}$ who conducted a phase I study of sorafenib plus carboplatin and paclitaxel and then focused on the activity of the regimen in patients with melanoma who were enrolled at the maximumtolerated dose, have provided some of the most intriguing results. Both untreated and previously treated patients with progressive growth of solid neoplasms before study enrollment were treated with fixed doses of carboplatin area under the curve 6 and paclitaxel $225 \mathrm{mg} / \mathrm{m}^{2}$ IV over 3 hours on day 1 followed by sorafenib at doses of 100,200, or $400 \mathrm{mg}$ twice daily from days 2 to 19 of a 3-week course. All dose iterations were well tolerated, and toxicity rates did not exceed those expected with carboplatin and paclitaxel in the absence of sorafenib. Sixty-seven patients with melanoma, 
most of whom were enrolled onto the phase II stage, have been treated. Of the 35 assessable patients with melanoma at the time of the report, 14 patients $(40 \%)$ had partial responses, all of which lasted for at least 6 months, and 15 patients (43\%) had stable disease as the best response. The median PFS time was estimated at 8.4 months. Of 25 patients whose mutational status was assessed, 15 (60\%) had ${ }^{V 599 E} B$-Raf, but the propensity to respond did not depend on $B$-Raf mutational status. Five (33\%) of 15 patients with ${ }^{V 599 E} B$-Raf and six $(60 \%)$ of 10 patients with wild-type B-Raf had partial responses. These results are impressive in light of the negligible activity of sorafenib as a single agent in patients with melanoma, implying that sorafenib may operate principally by inhibiting VEGF RTKs, perhaps by enhancing the penetration of cytotoxics into tumors and/or decreasing intratumoral pressure. A phase III study evaluating the paclitaxel-carboplatin regimen with and without sorafenib is planned.

In a phase I study of sorafenib and gemcitabine, the maximum-tolerated doses were gemcitabine $1,000 \mathrm{mg} / \mathrm{m}^{2}$ IV weekly for 7 of every 8 weeks, followed by weekly for 3 of every 4 weeks and sorafenib $400 \mathrm{mg}$ twice daily. ${ }^{223}$ Of 19 previously treated patients in the phase I study, two patients with ovarian carcinoma had partial responses; whereas one $(4.3 \%)$ of 23 previously untreated subjects treated in an expanded stage at the recommended dose had a partial response. ${ }^{223}$ No pharmacokinetic interactions were evident. Similarly, regimens consisting of sorafenib plus doxorubicin, irinotecan, or oxaliplatin were well tolerated, and pharmacokinetic interactions were not apparent. ${ }^{224-226}$ In a phase I study of sorafenib and doxorubicin, the principal toxicities were neutropenia and hand-foot syndrome, which did not preclude administering each agent at relevant doses (sorafenib $400 \mathrm{mg}$ twice daily and doxorubicin 60 $\mathrm{mg} / \mathrm{m}^{2}$ IV every 3 weeks). ${ }^{222}$ One patient with mesothelioma had a partial response, and 17 patients (52\%) had stable disease. Of note, four patients with hepatocellular carcinoma experienced stable disease lasting at least 12 months. Relevant doses of sorafenib (400 mg twice daily) and oxaliplatin $\left(130 \mathrm{mg} / \mathrm{m}^{2}\right.$ every 3 weeks) were well tolerated. ${ }^{227}$ Two patients with gastric carcinoma had partial responses lasting 14 and 21 weeks, and eight (42\%) of 19 assessable patients had stable disease. Pharmacokinetic interactions were not evident. The activity of these agents in patients with colorectal carcinoma and the feasibility of administering sorafenib with other therapeutics are being studied.

\section{Other Phrarmacologic Inhibitors of Raf Kinase}

Besides sorefanib, other small-molecule competitive inhibitors of the ATP-binding site of Raf proteins have been developed. L-779450 (Merck Pharmaceuticals Inc, Nutley, $\mathrm{NJ})$, a competitive inhibitor of the ATP-binding site of C-Raf, has demonstrated activity in the nanomolar range against
C-Raf-overexpressing human tumors in vitro and is much more effective at inhibiting the kinase activity of C-Raf and A-Raf than B-Raf. ${ }^{228,229}$ Likewise, the phenol substituted oxindole derivative SB203580 (GlaxoSmithKline Pharmaceuticals, Philadelphia, PA) inhibits C-Raf kinase in the low nanomolar range, but micromolar concentrations are required to inhibit ERK phosphorylation in cell culture. ${ }^{230,231}$ Interestingly, SB203580 may paradoxically activate C-Raf through an autocrine feedback loop as a result of MEK inhibition. ${ }^{232}$ Although C-Raf is a weak kinase, the significance of this observation is not known.

The tumor-inhibitory and cytotoxic effects of naturally occurring ansamycin antibiotics, particularly geldanamycin analogs that bind to Hsp90 and destabilize HSP90dependent proteins, produce impressive decrements in C-Raf expression. ${ }^{233}$ However, the effects of these agents on C-Raf may be nonspecific because $\mathrm{Hsp} 90$ plays a critical role in stabilizing and conferring functionality to a wide array of important cellular proteins such as v-Src, EGFR, HER-2/ $n e u, c d k 4, A k t 2$, and mutated $\mathrm{p} 53$, all of which are inhibited by the abrogation of Hsp90. ${ }^{233}$ Thus, the growth inhibitory and pro-apoptotic effects of geldanamycin analogs, such as 17-allylamino-17-demethoxygeldanamycin, may not be a result of direct effects on C-Raf alone, considering the pleiotropic effect of these compounds. ${ }^{234}$ Radicicol, a novel macrocyclic antibiotic isolated from the fungus Monosporium bonorden and potent inhibitor of $\mathrm{Hsp} 90$, has exhibited impressive tumor growth-inhibitory activity against a wide range of human tumor cell lines and xenografts, and both its antitumor and pharmaceutical properties are being optimized. ${ }^{233}$ Radicicol may, in part, inhibit tumor growth by destabilizing and depleting C-Raf. ${ }^{235}$ The $\mathrm{O}$-carbamoylmethyloxime derivatives may be superior to radicicol from both mechanistic and pharmaceutical perspectives. ${ }^{235}$

\section{Dominant Interfering DNA Constructs}

Dominant interfering DNA constructs that specifically target tumor cells with anti-raf genes have been described. One such method, which involves coupling a cationic lipidbased nanoparticle to an $\alpha \mathrm{v} \beta 3$ integrin ligand, seems to deliver genes to newly developing blood vessels of tumors that arise in mice after injection of melanoma cells. Hypothetically, by coupling a cDNA-encoding kinase-inactive $\mathrm{C}$-Raf to the nanoparticle, this dominant negative version of C-Raf is delivered to the neovasculature of developing tumors and induces apoptosis and tumor regression. Paradoxically, the inhibition of C-Raf may induce tumor regression not by affecting MEK/ERK activation, but by inhibiting the MEK kinase-independent role of C-Raf in promoting tumor survival. ${ }^{236}$ It is certainly possible that other therapeutics directed against C-Raf act in a similar fashion. 


\section{CONCLUSION}

It is hopeful that therapeutics designed based on understanding the primary molecular defects governing malignant cell proliferation will be more efficacious and less toxic than nonspecific cytotoxics. It is clear that aberrant forms of Raf are the principal drivers of many types of cancer. Furthermore, the potential therapeutic benefit conferred by therapeutics targeting Raf may not be limited to malignancies with mutant Raf because some cancers with wild-type Raf associated with growth factor receptor hyperactivity and/or Ras mutations are extraordinarily sensitive to Raf inhibition.

The knowledge that some tumors have driving target aberrations coupled with gene-sequencing data has provided the means to establish proof of principle about the validity of targets and/or targeted therapeutics. For Raf, rational patient enrichment strategies based on the presence of specific aberrations of Raf, Ras, and growth factor receptors can be formulated from the outset and dynamically optimized in the course of development. This is not to say that therapeutics targeting Raf will ultimately be restricted to niche indications because molecular aberrations are shared by many cancers. Instead, after proof of principle in cancers that are solely driven by a target aberration, such as melanoma and pancreatic carcinoma in the case of Raf and Ras, respectively, studies could then be conducted in tumors in which the target contributes to, but may not be the sole driver of, tumor growth. Although tumor regression rates may be negligible in these settings, the principal therapeutic effects of target inhibition in tumors with multiple contributory molecular aberrations may be best appreciated in randomized trials designed to detect differences in overall survival, PFS, and other end points that reflect tumor growth inhibition.

Although the early results with sorafenib have been encouraging, emerging clinical data do not irrefutably validate Raf as its relevant target. Instead, the intriguing activity of sorafenib in RCC, its lack of robust single-agent activity in melanoma, and its ability to enhance the activity of chemotherapeutics may reflect its greater potency at inhibiting VEGFR or other, as of yet unidentified, RTKs. To this end, the lack of robust activity with ASONs targeting Raf should not negate the importance of Raf as a therapeutic target because mutations of Raf and Ras were not assessed in studies of these agents and there are many unanswered questions about the validity of antisense strategies as therapeutic platforms. Although knowing the precise mechanism of sorafenib's antitumor activity may make little difference with regard to its ultimate utility, such information may be used to optimize the therapeutic indices of the next generation of therapeutics targeting Raf. In concert with clinical evaluations, Ras/Raf gene sequencing studies and assessments of relevant biologic markers may facilitate these efforts. Most importantly, the role of Raf in driving tumor proliferation must be further understood. Issues pertaining to the structural and functional basis of Raf and Ras mutations and their interrelationships and roles in tumorigenesis, proliferation, and cell survival must be addressed to develop more effective therapeutics against Raf and related targets.

\section{Authors' Disclosures of Potential Conflicts of Interest}

Although all authors completed the disclosure declaration, the following authors or their immediate family members indicated a financial interest. No conflict exists for drugs or devices used in a study if they are not being evaluated as part of the investigation. For a detailed description of the disclosure categories, or for more information about ASCO's conflict of interest policy, please refer to the Author Disclosure Declaration and the Disclosures of Potential Conflicts of Interest section in Information for Contributors.

\begin{tabular}{|c|c|c|c|c|c|c|c|c|}
\hline Authors & Employment & Leadership & Consultant & Stock & Honoraria & Research Funds & Testimony & Other \\
\hline Amita Patnaik & & & Genentech $(A)$ & & & & & \\
\hline Eric K. Rowinsky & & & & & & Bayer (C) & & \\
\hline \multicolumn{9}{|c|}{ Dollar Amount Codes } \\
\hline
\end{tabular}

\section{REFERENCES}

1. Khosravi-Far R, Der CJ: The Ras signal transduction pathway. Cancer Metastasis Rev 13:67-89, 1994

2. Campbell SL, Khosravi-Far R, Rossman $\mathrm{KL}$, et al: Increasing complexity of Ras signaling. Oncogene 17:1395-1413, 1998

3. Vojtek AB, Der CJ: Increasing complexity of the Ras signaling pathway. J Biol Chem 273: 19925-19928, 1998

4. Chong $\mathrm{H}$, Vikis HG, Guan KL: Mechanisms of regulating the Raf kinase family. Cell Signal 15:463-469, 2003
5. Joneson T, Bar-Sagi D: Ras effectors and their role in mitogenesis and oncogenesis. $\mathrm{J} \mathrm{Mol}$ Med 75:587-593, 1997

6. Heidecker G, Huleihel M, Cleveland JL, et al: Mutational activation of c-raf-1 and definition of the minimal transforming sequence. Mol Cell Biol 10:2503-2512, 1990

7. Schaap D, van der Wal J, Howe LR, et al: A dominant-negative mutant of raf blocks mitogenactivated protein kinase activation by growth factors and oncogenic p21ras. J Biol Chem 268: 20232-20236, 1993

8. Yuen ST, Davies $H$, Chan $T L$, et al: Similarity of the phenotypic patterns associated with
BRAF and KRAS mutations in colorectal neoplasia. Cancer Res 62:6451-6455, 2002

9. Davies H, Bignell GR, Cox C, et al: Mutations of the BRAF gene in human cancer. Nature 417:949-954, 2002

10. Storm SM, Rapp UR: Oncogene activation: C-raf-1 gene mutations in experimental and naturally occurring tumors. Toxicol Lett 67:201210, 1993

11. Mercer $K E$, Pritchard $C A$ : Raf proteins and cancer: B-Raf is identified as a mutational target. Biochim Biophys Acta 1653:25-40, 2003

12. Sommerer $F$, Vieth $M$, Markwarth $A$, et al: Mutations of BRAF and KRAS2 in the development 
of Barrett's adenocarcinoma. Oncogene 23:554558, 2004

13. Callans LS, Naama $H$, Khandelwal M, et al: Raf-1 protein expression in human breast cancer cells. Ann Surg Oncol 2:38-42, 1995

14. Rajagopalan $H$, Bardelli $A$, Lengauer $C$, et al: Tumorigenesis: RAF/RAS oncogenes and mismatch-repair status. Nature 418:934, 2002

15. Nikiforova MN, Kimura ET, Gandhi $M$, et al: BRAF mutations in thyroid tumors are restricted to papillary carcinomas and anaplastic or poorly differentiated carcinomas arising from papillary carcinomas. J Clin Endocrinol Metab 88:5399-5404, 2003

16. Kimura ET, Nikiforova MN, Zhu Z, et al: High prevalence of BRAF mutations in thyroid cancer: Genetic evidence for constitutive activation of the RET/PTC-RAS-BRAF signaling pathway in papillary thyroid carcinoma. Cancer Res 63:1454-1457, 2003

17. Pollock PM, Meltzer PS: A genomebased strategy uncovers frequent BRAF mutations in melanoma. Cancer Cell 2:5-7, 2002

18. Cohen $Y$, Xing $M$, Mambo $E$, et al: BRAF mutation in papillary thyroid carcinoma. J Natl Cancer Inst 95:625-627, 2003

19. Cohen MS, Hussain HB, Moley JF: Inhibition of medullary thyroid carcinoma cell proliferation and RET phosphorylation by tyrosine kinase inhibitors. Surgery 132:960-967, 2002

20. Singer G, Oldt R III, Cohen $Y$, et al: Mutations in BRAF and KRAS characterize the development of low-grade ovarian serous carcinoma. J Natl Cancer Inst 95:484-486, 2003

21. Tannapfel A, Sommerer F, Benicke M, et al: Mutations of the BRAF gene in cholangiocarcinoma but not in hepatocellular carcinoma. Gut 52:706-712, 2003

22. Lee JW, Soung YH, Park WS, et al: BRAF mutations in acute leukemias. Leukemia 18:170172, 2004

23. Weber A, Langhanki L, Sommerer F, et al: Mutations of the BRAF gene in squamous cell carcinoma of the head and neck. Oncogene 22:4757-4759, 2003

24. Brose MS, Volpe $P$, Feldman $M$, et al: BRAF and RAS mutations in human lung cancer and melanoma. Cancer Res 62:6997-7000, 2002

25. Lee $\mathrm{SH}$, Lee JW, Soung YH, et al: BRAF and KRAS mutations in stomach cancer. Oncogene 22:6942-6945, 2003

26. Gemignani $M L$, Schlaerth $A C$, Bogomolniy $F$, et al: Role of KRAS and BRAF gene mutations in mucinous ovarian carcinoma. Gynecol Oncol 90: 378-381, 2003

27. Lee JW, Yoo NJ, Soung YH, et al: BRAF mutations in non-Hodgkin's lymphoma. Br J Cancer 89:1958-1960, 2003

28. Oka H, Chatani $Y$, Hoshino $R$, et al: Constitutive activation of mitogen-activated protein (MAP) kinases in human renal cell carcinoma. Cancer Res 55:4182-4187, 1995

29. Carson EB, McMahon M, Baylin SB, et al: Ret gene silencing is associated with Raf-1induced medullary thyroid carcinoma cell differentiation. Cancer Res 55:2048-2052, 1995

30. McFarlin DR, Gould MN: Rat mammary carcinogenesis induced by in situ expression of constitutive Raf kinase activity is prevented by tethering Raf to the plasma membrane. Carcinogenesis 24:1149-1153, 2003
31. Kerkhoff E, Fedorov LM, Siefken $R$, et al: Lung-targeted expression of the c-Raf-1 kinase in transgenic mice exposes a novel oncogenic character of the wild-type protein. Cell Growth Differ 11:185-190, 2000

32. Graziano SL, Pfeifer AM, Testa JR, et al: Involvement of the RAF1 locus, at band 3p25, in the $3 p$ deletion of small-cell lung cancer. Genes Chromosomes Cancer 3:283-293, 1991

33. Patel BK, Ray $S$, Whiteside $T L$, et al: Correlation of constitutive activation of raf- 1 with morphological transformation and abrogation of tyrosine phosphorylation of distinct sets of proteins in human squamous carcinoma cells. Mol Carcinog 18:1-6, 1997

34. Riva C, Lavieille JP, Reyt E, et al: Differential c-myc, c-jun, c-raf and p53 expression in squamous cell carcinoma of the head and neck: Implication in drug and radioresistance. Eur J Cancer B Oral Oncol 31B:384-391, 1995

35. Ikeda S, Sumii H, Akiyama K, et al: Amplification of both c-myc and c-raf-1 oncogenes in a human osteosarcoma. Jpn J Cancer Res 80: 6-9, 1989

36. Mitsunobu F, Fukui $M$, Oda $T$, et al: $A$ mechanism of c-raf-1 activation: Fusion of the lipocortin II amino-terminal sequence with the c-raf-1 kinase domain. Oncogene 4:437-442, 1989

37. LaRocca RV, Rosenblum M, Westermark $B$, et al: Patterns of proto-oncogene expression in human glioma cell lines. J Neurosci Res 24: 97-106, 1989

38. Fukui M, Yamamoto $T$, Kawai $S$, et al: Molecular cloning and characterization of an activated human c-raf-1 gene. Mol Cell Biol 7:17761781, 1987

39. Korshunov A, Neben K, Wrobel G, et al: Gene expression patterns in ependymomas correlate with tumor location, grade, and patient age. Am J Pathol 163:1721-1727, 2003

40. Ting LP, Jeng KS, Chou CK, et al: Expression of oncogenes in human hepatoma cell lines. Zhonghua Min Guo Wei Sheng Wu Ji Mian Yi Xue Za Zhi 21:141-150, 1988

41. Jenke HS, Deml E, Oesterle D: C-raf expression in early rat liver tumorigenesis after promotion with polychlorinated biphenyls or phenobarbital. Xenobiotica 24:569-580, 1994

42. Beer DG, Neveu MJ, Paul DL, et al: Expression of the c-raf protooncogene, gammaglutamyltranspeptidase, and gap junction protein in rat liver neoplasms. Cancer Res 48:1610-1617, 1988

43. Berger $\mathrm{DH}$, Jardines $L A$, Chang $H$, et al: Activation of Raf-1 in human pancreatic adenocarcinoma. J Surg Res 69:199-204, 1997

44. Rowinsky EK, Windle JJ, Von Hoff DD: Ras protein farnesyltransferase: A strategic target for anticancer therapeutic development. J Clin Oncol 17:3631-3652, 1999

45. Yarden Y: The EGFR family and its ligands in human cancer: Signalling mechanisms and therapeutic opportunities. Eur J Cancer 37: S3-S8, 2001 (suppl 4)

46. Boguski MS, McCormick F: Proteins reg ulating Ras and its relatives. Nature 366:643-654 1993

47. English JM, Cobb MH: Pharmacological inhibitors of MAPK pathways. Trends Pharmacol Sci 23:40-45, 2002
48. Kohno M, Pouyssegur J: Pharmacological inhibitors of the ERK signaling pathway: Application as anticancer drugs. Prog Cell Cycle Res 5:219-224, 2003

49. Liebmann C: Regulation of MAP kinase activity by peptide receptor signalling pathway Paradigms of multiplicity. Cell Signal 13:777-785, 2001

50. Lewis TS, Shapiro PS, Ahn NG: Signal transduction through MAP kinase cascades. Adv Cancer Res 74:49-139, 1998

51. Kerkhoff E, Rapp UR: Cell cycle targets of Ras/Raf signalling. Oncogene 17:1457-1462, 1998

52. Chang F, Steelman LS, Shelton JG, et al: Regulation of cell cycle progression and apopto sis by the Ras/Raf/MEK/ERK pathway. Int J Oncol 22:469-480, 2003

53. Bos JL: Ras oncogenes in human cancer: A review. Cancer Res 49:4682-4689, 1989

54. Miyakis S, Sourvinos G, Spandidos DA: Differential expression and mutation of the ras family genes in human breast cancer. Biochem Biophys Res Commun 251:609-612, 1998

55. McCormick F: Ras biology in atomic detail. Nat Struct Biol 3:653-655, 1996

56. Hancock JF, Paterson H, Marshall CJ: A polybasic domain or palmitoylation is required in addition to the CAAX motif to localize p21ras to the plasma membrane. Cell 63:133-139, 1990

57. Kato K, Cox AD, Hisaka MM, et al: Isoprenoid addition to Ras protein is the critica modification for its membrane association and transforming activity. Proc Natl Acad Sci U S A 89:6403-6407, 1992

58. Polakis P, McCormick F: Interactions between p21ras proteins and their GTPase activat ing proteins. Cancer Surv 12:25-42, 1992

59. Clark GJ, Cox AD, Graham SM, et al: Biological assays for Ras transformation. Methods Enzymol 255:395-412, 1995

60. Clark GJ, Der CJ: Ras Proto-Oncogene Activation in Human Malignancy. Totowa, NJ, Humana Press, 1995

61. Barbacid M: Ras genes. Annu Rev Biochem 56:779-827, 1987

62. Gibbs JB, Oliff A: The potential of farnesyltransferase inhibitors as cancer chemotherapeutics. Annu Rev Pharmacol Toxicol 37: 143-166, 1997

63. Omer CA, Anthony NJ, Buser-Doepner $\mathrm{CA}$, et al: Farnesyl: Proteintransferase inhibitors as agents to inhibit tumor growth. Biofactors 6:359-366, 1997

64. Whyte DB, Kirschmeier P, Hockenberry $\mathrm{TN}$, et al: $\mathrm{K}$ - and $\mathrm{N}$-Ras are geranylgeranylated in cells treated with farnesyl protein transferase inhibitors. J Biol Chem 272:14459-14464, 1997

65. Rowell CA, Kowalczyk JJ, Lewis MD, et al: Direct demonstration of geranylgeranylation and farnesylation of Ki-Ras in vivo. J Biol Chem 272:14093-14097, 1997

66. Prendergast GC, Oliff A: Farnesyltransferase inhibitors: Antineoplastic properties, mechanisms of action, and clinical prospects. Semin Cancer Biol 10:443-452, 2000

67. Marshall CJ: Ras effectors. Curr Opin Cel Biol 8:197-204, 1996

68. Khosravi-Far R, Campbell S, Rossman KL, et al: Increasing complexity of Ras signal transduction: Involvement of Rho family proteins. Adv Cancer Res 72:57-107, 1998 
69. Smeal T, Binetruy B, Mercola DA, et al: Oncogenic and transcriptional cooperation with Ha-Ras requires phosphorylation of c-Jun on serines 63 and 73. Nature 354:494-496, 1991

70. Binetruy B, Smeal T, Karin M: Ha-Ras augments c-Jun activity and stimulates phosphorylation of its activation domain. Nature 351 : 122-127, 1991

71. Pulverer BJ, Kyriakis JM, Avruch J, et al: Phosphorylation of c-jun mediated by MAP kinases. Nature 353:670-674, 1991

72. Derijard B, Raingeaud J, Barrett $T$, et al: Independent human MAP-kinase signal transduction pathways defined by MEK and MKK isoforms. Science 267:682-685, 1995

73. Bagrodia S, Derijard B, Davis RJ, et al: Cdc42 and PAK-mediated signaling leads to Jun kinase and p38 mitogen-activated protein kinase activation. J Biol Chem 270:27995-27998, 1995

74. Robinson MJ, Cobb MH: Mitogenactivated protein kinase pathways. Curr Opin Cell Biol 9:180-186, 1997

75. Dhanasekaran N, Premkumar Reddy E: Signaling by dual specificity kinases. Oncogene 17:1447-1455, 1998

76. Schaeffer HJ, Weber MJ: Mitogenactivated protein kinases: Specific messages from ubiquitous messengers. Mol Cell Biol 19: 2435-2444, 1999

77. Zhang XF, Settleman J, Kyriakis JM, et al: Normal and oncogenic p21ras proteins bind to the amino-terminal regulatory domain of c-Raf- 1 . Nature 364:308-313, 1993

78. Avruch J, Khokhlatchev A, Kyriakis JM, et al: Ras activation of the Raf kinase: Tyrosine kinase recruitment of the MAP kinase cascade. Recent Prog Horm Res 56:127-155, 2001

79. Marais $R$, Light $Y$, Mason $C$, et al: Requirement of Ras-GTP-Raf complexes for activation of Raf-1 by protein kinase C. Science 280 : 109-112, 1998

80. Stokoe D, Macdonald SG, Cadwallader K, et al: Activation of Raf as a result of recruitment to the plasma membrane. Science 264:14631467, 1994

81. Pritchard $C$, McMahon M: Raf revealed in life-or-death decisions. Nat Genet 16:214-215, 1997

82. Morrison DK, Cutler RE: The complexity of Raf-1 regulation. Curr Opin Cell Biol 9:174179, 1997

83. Marshall CJ: Cell signaling: Raf gets it together. Nature 383:127-128, 1996

84. Leevers SJ, Paterson HF, Marshall CJ: Requirement for Ras in Raf activation is overcome by targeting Raf to the plasma membrane. Nature 369:411-414, 1994

85. Mason CS, Springer CJ, Cooper RG, et al: Serine and tyrosine phosphorylations cooperate in Raf-1, but not B-Raf activation. Embo J 18: 2137-2148, 1999

86. Stancato LF, Sakatsume M, David M, et al: Beta interferon and oncostatin $M$ activate Raf-1 and mitogen-activated protein kinase through a JAK1-dependent pathway. Mol Cell Biol 17:3833-3840, 1997

87. Farrar MA, Alberol I, Perlmutter RM: Activation of the Raf-1 kinase cascade by coumermycin-induced dimerization. Nature 383: 178-181, 1996
88. Kolch W, Heidecker G, Kochs G, et al: Protein kinase $\mathrm{C}$ alpha activates RAF-1 by direct phosphorylation. Nature 364:249-252, 1993

89. Yao B, Zhang Y, Delikat S, et al: Phosphorylation of Raf by ceramide-activated protein kinase. Nature 378:307-310, 1995

90. Kasid U, Suy S, Dent $P$, et al: Activation of Raf by ionizing radiation. Nature 382:813-816, 1996

91. Hoyos B, Imam A, Korichneva I, et al: Activation of c-Raf kinase by ultraviolet light: Regulation by retinoids. J Biol Chem 277:2394923957, 2002

92. Tilbrook PA, Colley SM, McCarthy DJ, et al: Erythropoietin-stimulated Raf-1 tyrosine phosphorylation is associated with the tyrosine kinase Lyn in J2E erythroleukemic cells. Arch Biochem Biophys 396:128-132, 2001

93. Luo Z, Tzivion G, Belshaw PJ, et al: Oligomerization activates c-Raf-1 through a Rasdependent mechanism. Nature 383:181-185, 1996

94. Weber CK, Slupsky JR, Kalmes HA, et al: Active Ras induces heterodimerization of cRaf and BRaf. Cancer Res 61:3595-3598, 2001

95. Hekman M, Hamm H, Villar AV, et al: Associations of B- and C-Raf with cholesterol phosphatidylserine, and lipid second messengers: Preferential binding of Raf to artificial lipid rafts. J Biol Chem 277:24090-24102, 2002

96. Cook SJ, McCormick F: Inhibition by cAMP of Ras-dependent activation of Raf. Science 262:1069-1072, 1993

97. Hafner S, Adler HS, Mischak $\mathrm{H}$, et al: Mechanism of inhibition of Raf- 1 by protein kinase A. Mol Cell Biol 14:6696-6703, 1994

98. Reusch HP, Zimmermann S, Schaefer M, et al: Regulation of Raf by Akt controls growth and differentiation in vascular smooth muscle cells. J Biol Chem 276:33630-33637, 2001

99. Jansen HW, Lurz R, Bister $K$, et al: Homologous cell-derived oncogenes in avian carcinoma virus $\mathrm{MH} 2$ and murine sarcoma virus 3611. Nature 307:281-284, 1984

100. Sutrave $P$, Bonner TI, Rapp UR, et al: Nucleotide sequence of avian retroviral oncogene v-mil: Homologue of murine retroviral oncogene v-raf. Nature 309:85-88, 1984

101. Kan NC, Flordellis CS, Mark GE, et al: A common onc gene sequence transduced by avian carcinoma virus $\mathrm{MH} 2$ and by murine sarcoma virus 3611. Science 223:813-816, 1984

102. Rapp UR, Goldsborough MD, Mark GE, et al: Structure and biological activity of $\mathrm{V}$-raf, a unique oncogene transduced by a retrovirus. Proc Natl Acad Sci U S A 80:4218-4222, 1983

103. Calogeraki I, Barnier JV, Eychene $A$, et al: Genomic organization and nucleotide sequence of the coding region of the chicken $\mathrm{c}-\mathrm{Rmil}(\mathrm{B}$ raf-1) proto-oncogene. Biochem Biophys Res Commun 193:1324-1331, 1993

104. Eychene A, Barnier JV, Apiou F, et al: Chromosomal assignment of two human B-raf(Rmil) proto-oncogene loci: B-raf-1 encoding the p94Braf/Rmil and B-raf-2, a processed pseudogene. Oncogene 7:1657-1660, 1992

105. Jaiswal RK, Weissinger $E$, Kolch W, et al: Nerve growth factor-mediated activation of the mitogen-activated protein (MAP) kinase cascade involves a signaling complex containing B-Raf and HSP90. J Biol Chem 271:23626-23629, 1996
106. Barnier JV, Papin C, Eychene A, et al: The mouse B-raf gene encodes multiple protein isoforms with tissue-specific expression. J Bio Chem 270:23381-23389, 1995

107. Papin C, Barnier JV, Eychene A, et al: B-raf gene encodes for multiple isoforms with Mek-1 kinase activity. C R Seances Soc Biol Fil 189:71-85, 1995

108. Nantel A, Huber M, Thomas DY: Localization of endogenous Grb10 to the mitochondria and its interaction with the mitochondrialassociated Raf-1 pool. J Biol Chem 274:35719 35724, 1999

109. Majewski $M$, Nieborowska-Skorska $M$, Salomoni $\mathrm{P}$, et al: Activation of mitochondria Raf-1 is involved in the antiapoptotic effects of Akt. Cancer Res 59:2815-2819, 1999

110. Wang HG, Rapp UR, Reed JC: Bcl-2 targets the protein kinase Raf-1 to mitochondria Cell 87:629-638, 1996

111. Yuryev A, Ono M, Goff SA, et al: Isoformspecific localization of A-RAF in mitochondria. Mol Cell Biol 20:4870-4878, 2000

112. Morice $C$, Nothias F, Konig S, et al: Raf-1 and B-Raf proteins have similar regional distributions but differential subcellular localization in adult rat brain. Eur J Neurosci 11:1995-2006, 1999

113. Hagemann C, Rapp UR: Isotype-specific functions of Raf kinases. Exp Cell Res 253:34-46, 1999

114. Pritchard CA, Bolin L, Slattery $R$, et al: Post-natal lethality and neurological and gastrointestinal defects in mice with targeted disrup tion of the A-Raf protein kinase gene. Curr Biol 6:614-617, 1996

115. Houslay MD, Kolch W: Cell-type specific integration of cross-talk between extracellular signal-regulated kinase and CAMP signaling. Mol Pharmacol 58:659-668, 2000

116. Vojtek AB, Hollenberg SM, Cooper JA: Mammalian Ras interacts directly with the serine/threonine kinase Raf. Cell 74:205-214, 1993

117. Drugan JK, Khosravi-Far R, White MA, et al: Ras interaction with two distinct binding domains in Raf-1 may be required for Ras transformation. J Biol Chem 271:233-237, 1996

118. Brtva TR, Drugan JK, Ghosh $S$, et al: Two distinct Raf domains mediate interaction with Ras. J Biol Chem 270:9809-9812, 1995

119. Guan $K L$, Figueroa $C$, Brtva $T R$, et al: Negative regulation of the serine/threonine $\mathrm{ki}$ nase B-Raf by Akt. J Biol Chem 275:2735427359, 2000

120. Morrison DK, Heidecker G, Rapp UR, et al: Identification of the major phosphorylation sites of the Raf-1 kinase. J Biol Chem 268 17309-17316, 1993

121. Zimmermann S, Moelling K: Phosphorylation and regulation of Raf by Akt (protein kinase B). Science 286:1741-1744, 1999

122. Mikula M, Schreiber M, Husak Z, et al: Embryonic lethality and fetal liver apoptosis in mice lacking the c-raf-1 gene. Embo J 20:19521962, 2001

123. Wu X, Noh SJ, Zhou G, et al: Selective activation of MEK1 but not MEK2 by A-Raf from epidermal growth factor-stimulated Hela cells J Biol Chem 271:3265-3271, 1996 
124. Marais $R$, Light $Y$, Paterson $H F$, et al: Differential regulation of Raf-1, A-Raf, and B-Raf by oncogenic ras and tyrosine kinases. J Biol Chem 272:4378-4383, 1997

125. Pritchard CA, Samuels ML, Bosch E, et al: Conditionally oncogenic forms of the A-Raf and B-Raf protein kinases display different biological and biochemical properties in NIH 3T3 cells. Mol Cell Biol 15:6430-6442, 1995

126. Kubicek $M$, Pacher $M$, Abraham $D$, et al: Dephosphorylation of Ser-259 regulates Raf-1 membrane association. J Biol Chem 277:7913 7919, 2002

127. Chuang E, Barnard D, Hettich $L$, et al: Critical binding and regulatory interactions between Ras and Raf occur through a small, stable $\mathrm{N}$-terminal domain of Raf and specific Ras effector residues. Mol Cell Biol 14:5318-5325, 1994

128. Voice JK, Klemke RL, Le A, et al: Four human ras homologs differ in their abilities to activate Raf-1, induce transformation, and stimulate cell motility. J Biol Chem 274:17164-17170, 1999

129. Okada $T, H u C D$, Jin $T G$, et al: The strength of interaction at the Raf cysteine-rich domain is a critical determinant of response of Raf to Ras family small GTPases. Mol Cell Biol 19:6057-6064, 1999

130. Yamamori B, Kuroda S, Shimizu K, et al: Purification of a Ras-dependent mitogenactivated protein kinase kinase kinase from bovine brain cytosol and its identification as a complex of B-Raf and 14-3-3 proteins. J Biol Chem 270:11723-11726, 1995

131. Vossler MR, Yao H, York RD, et al: CAMP activates MAP kinase and Elk-1 through a B-Rafand Rap1-dependent pathway. Cell 89:73-82, 1997

132. York RD, Yao $H$, Dillon $T$, et al: Rap1 mediates sustained MAP kinase activation induced by nerve growth factor. Nature 392:622626, 1998

133. Bos JL, de Rooij J, Reedquist KA: Rap1 signalling: Adhering to new models. Nat Rev Mol Cell Biol 2:369-377, 2001

134. Chaudhary A, King WG, Mattaliano MD, et al: Phosphatidylinositol 3-kinase regulates Raf1 through Pak phosphorylation of serine 338. Curr Biol 10:551-554, 2000

135. Diaz B, Barnard D, Filson A, et al: Phosphorylation of Raf-1 serine 338-serine 339 is an essential regulatory event for Ras-dependent activation and biological signaling. Mol Cell Biol 17:4509-4516, 1997

136. King AJ, Sun $H$, Diaz B, et al: The protein kinase Pak3 positively regulates Raf-1 activity through phosphorylation of serine 338. Nature 396:180-183, 1998

137. Dhillon AS, Meikle S, Yazici Z, et al: Regulation of Raf-1 activation and signalling by dephosphorylation. Embo J 21:64-71, 2002

138. Zhang BH, Tang ED, Zhu T, et al: Serumand glucocorticoid-inducible kinase SGK phosphorylates and negatively regulates B-Raf. J Biol Chem 276:31620-31626, 2001

139. Dhillon AS, Meikle S, Peyssonnaux C, et al: A Raf-1 mutant that dissociates MEK/extracellular signal-regulated kinase activation from malignant transformation and differentiation but not proliferation. Mol Cell Biol 23:1983-1993, 2003
140. Chong H, Lee J, Guan KL: Positive and negative regulation of Raf kinase activity and function by phosphorylation. Embo J 20:37163727, 2001

141. Fabian JR, Daar IO, Morrison DK: Critical tyrosine residues regulate the enzymatic and biological activity of Raf-1 kinase. Mol Cell Biol 13:7170-7179, 1993

142. Sun $H$, King AJ, Diaz HB, et al: Regulation of the protein kinase Raf- 1 by oncogenic Ras through phosphatidylinositol 3-kinase, Cdc42/ Rac and Pak. Curr Biol 10:281-284, 2000

143. Campbell S, Otis M, Cote M, et al: Connection between integrins and cell activation in rat adrenal glomerulosa cells: A role for Arg-GlyAsp peptide in the activation of the p42/ p44(mapk) pathway and intracellular calcium. Endocrinology 144:1486-1495, 2003

144. Zhang BH, Guan KL: Activation of B-Raf kinase requires phosphorylation of the conserved residues Thr598 and Ser601. Embo J 19:5429-5439, 2000

145. Wojnowski L, Stancato LF, Larner AC, et al: Overlapping and specific functions of Braf and Craf-1 proto-oncogenes during mouse embryogenesis. Mech Dev 91:97-104, 2000

146. Dent $P$, Haser W, Haystead TA, et al: Activation of mitogen-activated protein kinase kinase by v-Raf in NIH 3 T3 cells and in vitro. Science 257:1404-1407, 1992

147. Catling $A D$, Reuter $C W$, Cox $M E$, et al: Partial purification of a mitogen-activated protein kinase kinase activator from bovine brain: Identification as B-Raf or a B-Raf-associated activity J Biol Chem 269:30014-30021, 1994

148. Catling $A D$, Schaeffer $H J$, Reuter $C W$, et al: A proline-rich sequence unique to MEK1 and MEK2 is required for raf binding and regulates MEK function. Mol Cell Biol 15:5214-5225, 1995

149. Howe LR, Leevers SJ, Gomez N, et al: Activation of the MAP kinase pathway by the protein kinase raf. Cell 71:335-342, 1992

150. Kyriakis JM, App H, Zhang XF, et al: Raf-1 activates MAP kinase-kinase. Nature 358:417421, 1992

151. Jaiswal RK, Moodie SA, Wolfman A, et al: The mitogen-activated protein kinase cascade is activated by B-Raf in response to nerve growth factor through interaction with p21ras. Mol Cell Biol 14:6944-6953, 1994

152. Yan M, Templeton DJ: Identification of 2 serine residues of MEK-1 that are differentially phosphorylated during activation by raf and MEK kinase. J Biol Chem 269:19067-19073, 1994

153. Reuter CW, Catling $A D$, Jelinek $T$, et al: Biochemical analysis of MEK activation in NIH3T3 fibroblasts: Identification of B-Raf and other activators. J Biol Chem 270:7644-7655, 1995

154. Kolch W: Meaningful relationships: The regulation of the Ras/Raf/MEK/ERK pathway by protein interactions. Biochem J 351:289-305, 2000

155. Baumann B, Weber CK, Troppmair J, et al: Raf induces NF-kappaB by membrane shuttle kinase MEKK1, a signaling pathway critical for transformation. Proc Natl Acad Sci U S A 97: 4615-4620, 2000

156. Wang S, Ghosh RN, Chellappan SP: Raf-1 physically interacts with $\mathrm{Rb}$ and regulates its function: A link between mitogenic signaling and cell cycle regulation. Mol Cell Biol 18:7487-7498 1998

157. Wang HG, Miyashita T, Takayama $S$, et al: Apoptosis regulation by interaction of $\mathrm{Bcl}-2$ protein and Raf-1 kinase. Oncogene 9:2751-2756, 1994

158. Papin C, Denouel A, Calothy G, et al: Identification of signalling proteins interacting with B-Raf in the yeast two-hybrid system. Oncogene 12:2213-2221, 1996

159. Ahn NG, Seger $R$, Bratlien $R L$, et al: Multiple components in an epidermal growth factor-stimulated protein kinase cascade: In vitro activation of a myelin basic protein/microtubuleassociated protein 2 kinase. J Biol Chem 266 4220-4227, 1991

160. Crews CM, Alessandrini $A$, Erikson RL: The primary structure of MEK, a protein kinase that phosphorylates the ERK gene product. Science 258:478-480, 1992

161. Morrison DK: KSR: A MAPK scaffold of the Ras pathway? J Cell Sci 114:1609-1612, 2001

162. Michaud NR, Therrien M, Cacace A, et al: KSR stimulates Raf-1 activity in a kinaseindependent manner. Proc Natl Acad Sci U S A 94:12792-12796, 1997

163. Galaktionov K, Jessus C, Beach D: Raf1 interaction with $\mathrm{Cdc} 25$ phosphatase ties mitogenic signal transduction to cell cycle activation Genes Dev 9:1046-1058, 1995

164. Jinno S, Suto K, Nagata A, et al: Cdc25A is a novel phosphatase functioning early in the cell cycle. Embo J 13:1549-1556, 1994

165. Janosch $P$, Kieser $A$, Eulitz $M$, et al: The Raf-1 kinase associates with vimentin kinases and regulates the structure of vimentin filaments. FASEB J 14:2008-2021, 2000

166. Li S, Sedivy JM: Raf-1 protein kinase activates the NF-kappa B transcription factor by dissociating the cytoplasmic NF-kappa B-I kappa B complex. Proc Natl Acad Sci U S A 90:92479251, 1993

167. Peruzzi F, Prisco $M$, Dews $M$, et al: Multiple signaling pathways of the insulin-like growth factor 1 receptor in protection from apoptosis. Mol Cell Biol 19:7203-7215, 1999

168. Patriotis $C$, Russeva MG, Lin JH, et al: Tpl-2 induces apoptosis by promoting the assembly of protein complexes that contain caspase-9, the adapter protein TVl-1, and procaspase-3. J Cell Physiol 187:176-187, 2001

169. Chen J, Fujii K, Zhang $L$, et al: Raf-1 promotes cell survival by antagonizing apoptosis signal-regulating kinase 1 through a MEK-ERK independent mechanism. Proc Natl Acad Sc U S A 98:7783-7788, 2001

170. Jamal S, Ziff EB: Raf phosphorylates p53 in vitro and potentiates p53-dependent transcriptional transactivation in vivo. Oncogene 10:20952101, 1995

171. Nilsson I, Hoffmann I: Cell cycle regulation by the Cdc25 phosphatase family. Prog Cell Cycle Res 4:107-114, 2000

172. Cornwell MM, Smith DE: A signal transduction pathway for activation of the mdr1 promoter involves the proto-oncogene c-raf kinase. J Biol Chem 268:15347-15350, 1993

173. Harris $P$, Morton CC, Guglielmi $P$, et al: Mapping by chromosome sorting of severa gene probes, including c-myc, to the derivative 
chromosomes of a 3;8 translocation associated with familial renal cancer. Cytometry 7:589-594, 1986

174. Miyamoto K, Tomita N, Ishii A, et al: Specific abnormalities of chromosome 14 in patients with acute type of adult T-cell leukemia/ lymphoma. Int J Cancer 40:461-468, 1987

175. Nagao $M$, Ishikawa $F$, Tahira $T$, et al: Activation of rat and human c-raf(-1) by rearrangement. Princess Takamatsu Symp 17:75-84, 1986

176. Huser M, Luckett J, Chiloeches A, et al: MEK kinase activity is not necessary for Raf-1 function. Embo J 20:1940-1951, 2001

177. Niehof M, Radziwill $G$, Klauser $S$, et al: A small peptide derived from the aminoterminus of c-Raf-1 inhibits c-Raf-1/Ras binding. Biochem Biophys Res Commun 206:46-50, 1995

178. Metzelaar-Blok JA, Jager MJ, Moghaddam $\mathrm{PH}$, et al: Frequent loss of heterozygosity on chromosome $6 p$ in uveal melanoma. Hum Immunol 60:962-969, 1999

179. Cohen Y, Goldenberg-Cohen N, Parrella $P$, et al: Lack of BRAF mutation in primary uveal melanoma. Invest Ophthalmol Vis Sci 44:28762878, 2003

180. Pollock PM, Harper UL, Hansen KS, et al: High frequency of BRAF mutations in nevi. Nat Genet 33:19-20, 2003

181. Takayama $T$, Ohi $M$, Hayashi $T$, et al: Analysis of K-ras, APC, and beta-catenin in aberrant crypt foci in sporadic adenoma, cancer, and familial adenomatous polyposis. Gastroenterology 121:599-611, 2001

182. Yamashita $N$, Minamoto $T$, Ochiai $A$, et al: Frequent and characteristic K-ras activation in aberrant crypt foci of colon: Is there preference among K-ras mutants for malignant progression? Cancer 75:1527-1533, 1995

183. Busca $R$, Abbe $P$, Mantoux $F$, et al: Ras mediates the cAMP-dependent activation of extracellular signal-regulated kinases (ERKs) in melanocytes. Embo J 19:2900-2910, 2000

184. lacovelli L, Capobianco L, Salvatore L, et al: Thyrotropin activates mitogen-activated protein kinase pathway in FRTL-5 by a cAMP-dependent protein kinase A-independent mechanism. Mol Pharmacol 60:924-933, 2001

185. Manning G, Whyte DB, Martinez $R$, et al: The protein kinase complement of the human genome. Science 298:1912-1934, 2002

186. Stanton VP Jr, Cooper GM: Activation of human raf transforming genes by deletion of normal amino-terminal coding sequences. Mol Cell Biol 7:1171-1179, 1987

187. Kasid U, Pfeifer A, Weichselbaum RR, et al: The raf oncogene is associated with a radiation-resistant human laryngeal cancer. Science 237:1039-1041, 1987

188. Yu X, Guo ZS, Marcu MG, et al: Modulation of p53, ErbB1, ErbB2, and Raf-1 expression in lung cancer cells by depsipeptide FR901228. J Natl Cancer Inst 94:504-513, 2002

189. Carter G, Lemoine NR: Antisense technology for cancer therapy: Does it make sense? Br J Cancer 67:869-876, 1993

190. Stephens AC, Rivers RP: Antisense oligonucleotide therapy in cancer. Curr Opin Mol Ther 5:118-122, 2003

191. Monia BP, Sasmor H, Johnston JF, et al: Sequence-specific antitumor activity of a phos- phorothioate oligodeoxyribonucleotide targeted to human C-raf kinase supports an antisense mechanism of action in vivo. Proc Natl Acad Sci U S A 93:15481-15484, 1996

192. Monia BP, Johnston JF, Geiger $T$, et al: Antitumor activity of a phosphorothioate antisense oligodeoxynucleotide targeted against C-raf kinase. Nat Med 2:668-675, 1996

193. Gokhale PC, McRae D, Monia BP, et al: Antisense raf oligodeoxyribonucleotide is a radiosensitizer in vivo. Antisense Nucleic Acid Drug Dev 9:191-201, 1999

194. Henry SP, Monteith D, Bennett F, et al: Toxicological and pharmacokinetic properties of chemically modified antisense oligonucleotide inhibitors of PKC-alpha and C-raf kinase. Anticancer Drug Des 12:409-420, 1997

195. Phillips JA, Craig SJ, Bayley D, et al: Pharmacokinetics, metabolism, and elimination of a 20-mer phosphorothioate oligodeoxynucleotide (CGP 69846A) after intravenous and subcutaneous administration. Biochem Pharmacol 54:657-668, 1997

196. Geary RS, Leeds JM, Fitchett J, et al: Pharmacokinetics and metabolism in mice of a phosphorothioate oligonucleotide antisense inhibitor of C-raf-1 kinase expression. Drug Metab Dispos 25:1272-1281, 1997

197. Cunningham CC, Holmlund JT, Schiller $\mathrm{JH}$, et al: A phase I trial of c-Raf kinase antisense oligonucleotide ISIS 5132 administered as a continuous intravenous infusion in patients with advanced cancer. Clin Cancer Res 6:1626-1631, 2000

198. Stevenson JP, Yao KS, Gallagher M, et al: Phase I clinical/pharmacokinetic and pharmacodynamic trial of the c-raf-1 antisense oligonucleotide ISIS 5132 (CGP 69846A). J Clin Oncol 17:2227-2236, 1999

199. Rudin CM, Holmlund J, Fleming GF, et al: Phase I trial of ISIS 5132, an antisense oligonucleotide inhibitor of c-raf-1, administered by 24 hour weekly infusion to patients with advanced cancer. Clin Cancer Res 7:1214-1220, 2001

200. Tolcher AW, Reyno L, Venner PM, et al: A randomized phase $\mathrm{II}$ and pharmacokinetic study of the antisense oligonucleotides ISIS 3521 and ISIS 5132 in patients with hormone-refractory prostate cancer. Clin Cancer Res 8:2530-2535, 2002

201. Cripps MC, Figueredo AT, Oza AM, et al: Phase II randomized study of ISIS 3521 and ISIS 5132 in patients with locally advanced or metastatic colorectal cancer: A National Cancer Institute of Canada Clinical Trials Group study. Clin Cancer Res 8:2188-2192, 2002

202. Oza AM, Elit L, Swenerton $K$, et al: Phase II study of CGP 69846A (ISIS 5132) in recurrent epithelial ovarian cancer: An NCIC Clinical Trials Group study (NCIC IND. 116). Gynecol Oncol 89:129-133, 2003

203. Coudert B, Anthoney A, Fiedler W, et al: Phase II trial with ISIS 5132 in patients with small-cell (SCLC) and non-small cell (NSCLC) lung cancer: A European Organization for Research and Treatment of Cancer (EORTC) Early Clinical Studies Group report. Eur J Cancer 37: 2194-2198, 2001

204. Bonner TI, Kerby SB, Sutrave $P$, et al: Structure and biological activity of human ho- mologs of the raf/mil oncogene. Mol Cell Bio 5:1400-1407, 1985

205. Wan PT, Garnett MJ, Roe SM, et al: Mechanism of activation of the RAF-ERK signaling pathway by oncogenic mutations of B-RAF. Cell 116:855-867, 2004

206. Wilhelm S, Chien DS: BAY 43-9006: Preclinical data. Curr Pharm Des 8:2255-2257, 2002

207. Choi YJ, Fanidi A, White $S$, et al: The novel inhibitor BAY 43-9006 blocks signaling and proliferation in b-Raf mutant and wild type melanoma and colorectal tumor cell lines. Presented at Am Assoc Cancer Res 94th Annual Meeting, Washington, DC, July11-14, 2003

208. Wilhelm S, Carter $C$, Tang $L$, et al: BAY 43-9006 exhibits broad spectrum anti-tumor activity and targets raf/MEK/ERK pathway and receptor tyrosine kinases involved in tumor progression and angiogenesis. Presented at the 2003 AACR-NCI-EORTC International Conference for Molecular Targets and Cancer Therapeutics, Boston, MA, November 17-21, 2003

209. Carter $C$, Deuringer $P$, et al: Investigators Brochure BAY 43-9006/ Raf Kinase Inhibitor Version No. 4.1. West Haven, CT, Bayer Pharmaceuticals Corporation, 2003

210. Wilhelm SM, Carter C, Tang LY, et al: BAY 43-9006 exhibits broad spectrum oral antitumor activity and targets the RAF/MEK/ERK pathway and receptor tyrosine kinases involved in tumor progression and angiogenesis. Cancer Res 64:7099-7109, 2004

211. Alavi A, Hood JD, Frausto $R$, et al: Role of Raf in vascular protection from distinct apoptotic stimuli. Science 301:94-96, 2003

212. Vincent $P$, Zhang $X$, Chen CM, et al: Preclinical chemotherapy with the Raf kinase inhibitor BAY 43-9006 in combination with gefitinib, vinorelbine, gemcitabine and doxorubicin Presented at Am Assoc Cancer Res 94th Annual Meeting, Washington, DC, July11-14, 2003

213. Lyons JF, Wilhelm S, Hibner $B$, et al: Discovery of a novel Raf kinase inhibitor. Endocr Relat Cancer 8:219-225, 2001

214. Activity of the Raf kinase inhibitor BAY 43-9006 in patients with advanced solid tumors. Clin Colorectal Cancer 3:16-18, 2003

215. Strumberg D, Voliotis D, Moeller JG, et al: Results of phase I pharmacokinetic and pharmacodynamic studies of the Raf kinase inhibitor BAY 43-9006 in patients with solid tumors. Int J Clin Pharmacol Ther 40:580-581, 2002

216. Hilger RA, Kredke S, Hedley D, et al: Inhibition of ERK phosphorylation in patients treated with the Raf kinase inhibitor BAY 439006. Eur J Cancer 38:S52-S53, 2002

217. Kopec JA, Abrahamowicz M, Esdaile JM: Randomized discontinuation trials: Utility and efficiency. J Clin Epidemiol 46:959-971, 1993

218. Ratain MJ, Flaherty $K$, Stadler WM, et al: Preliminary antitumor activity of BAY 43-9006 in metastatic renal cell carcinoma and other advanced refractory solid tumors in a phase I randomized discontinuation trial (RDT). J Clin Oncol 22:381s, 2004 (suppl; abstr 4501)

219. Ratain MJ, Eisen $T$, Stadler WM: Final findings from a Phase II, placebo-controlled, randomized discontinuation trial (RDT) of sorafenib (BAY 43-9006) in patients with advanced rena cell carcinoma (RCC). J Clin Oncol 23:388s, 2005 (suppl; abstr 4544) 
220. Escudier B, Szczylik C, Eisen T, et al: Randomized phase III trial of the Raf kinase and VEGFR inhibitor sorafenib (BAY 43-9006) in patients with advanced renal cell carcinoma (RCC). Proc Am Soc Clin Oncol 23:380s, 2005 (suppl; abstr LBA4510)

221. Ahmad $T$, Marias $R$, Pyle $L$, et al: BAY 43-9006 in patients with advanced melanoma: The Royal Marsden experience. J Clin Oncol 22:708s, 2004 (suppl; abstr 7506)

222. Flaherty KT, Brose M, Schuchter $L$, et al: Phase I/II trial of BAY 43-9006, carboplatin (C) and paclitaxel $(P)$ demonstrates preliminary antitumor activity in the expansion cohort of patients with metastatic melanoma. J Clin Oncol 22: 708s, 2004 (suppl; abstr 7507)

223. Siu LL, Takimoto $C H$, Awada $A$, et al: $A$ phase I/II trial of BAY 43-9006 and gemcitabine in advanced solid tumors and in advanced pancreatic cancer. J Clin Oncol 22:209s, 2004 (suppl; abstr 3059)

224. Richly $H$, Kupsch $P$, Passage $K$, et al: $A$ phase I clinical and pharmacokinetic study of the Raf kinase inhibitor (RKI) BAY 43-9006 administered in combination with doxorubicin in patients with solid tumors. Int $\mathrm{J}$ Clin Pharmacol The $41: 620-621,2003$
225. Heim M, Sharifi M, Hilger RA, et al: Antitumor effect and potentiation or reduction in cytotoxic drug activity in human colon carcinoma cells by the Raf kinase inhibitor (RKI) BAY 43-9006. Int J Clin Pharmacol Ther 41:616-617, 2003

226. Mross K, Steinbild S, Baas F, et al: Drugdrug interaction pharmacokinetic study with the Raf kinase inhibitor (RKI) BAY 43-9006 administered in combination with irinotecan (CPT-11) in patients with solid tumors. Int J Clin Pharmacol Ther 41:618-619, 2003

227. Kupsch $P$, Passarge $K$, Richly $H$, et al: Results of a phase I trial of BAY 43-9006 in combination with oxaliplatin in patients with refractory solid tumors. J Clin Oncol 22:209s, 2004 (suppl; abstr 3056

228. Heimbrook HE, Huber SM, Stirdivant $D$ et al: Identification of potent selective kinase inhibitors of Raf. Presented at Am Assoc Cancer Res 89th Annual Meeting, New Orleans, LA, March 28-April 1, 1998 (abstr 3793)

229. Shelton JG, Moye PW, Steelman LS, et al: Differential effects of kinase cascade inhibitors on neoplastic and cytokine-mediated cell proliferation. Leukemia 17:1765-1782, 2003
230. Lackey K, Cory M, Davis R, et al: The discovery of potent cRaf1 kinase inhibitors. Bioorg Med Chem Lett 10:223-226, 2000

231. Wood E, Crosby RM, Dickerson S, et al: A prodrug approach to the design of cRaf1 kinase inhibitors with improved cellular activity. Anticancer Drug Des 16:1-6, 2001

232. Hall-Jackson CA, Goedert $M$, Hedge $P$, et al: Effect of SB 203580 on the activity of C-Raf in vitro and in vivo. Oncogene 18:2047 2054, 1999

233. Maloney A, Workman P: HSP90 as a new therapeutic target for cancer therapy: The story unfolds. Expert Opin Biol Ther 2:3-24, 2002

234. Sausville EA, Tomaszewski JE, Ivy $P$ : Clinical development of 17-allylamino, 17demethoxy-geldanamycin. Curr Cancer Drug Targets 3:377-383, 2003

235. Ikuina $Y$, Amishiro $N$, Miyata $M$, et al: Synthesis and antitumor activity of nove O-carbamoylmethyloxime derivatives of radicicol. J Med Chem 46:2534-2541, 2003

236. Hood JD, Bednarski $M$, Frausto $R$, et al: Tumor regression by targeted gene delivery to the neovasculature. Science 296:2404-2407, 2002 